M1 in the collected urine samples, also the contribution from the diet to the overall exposure is to be considered negligible.

\section{Response to Reviewers:}

3RD REV (letter 19/12/2019)

Dear reviewers, all requested changes has been accepted and text amended accordingly.

see in detail

1.Delete heading "Conclusions", this journal has no such section. Concluding remarks should be put directly after end of results and discussion. DONE

2.Do not use justified text, but type left-aligned throughout the manuscript without automated hyphenation (?). Then please check if some typos (extra space etc) become visible and correct im necessary. DONE

3.Move "Acknowledgements" section directly before the reference list section DONE 4.Temperature and other units: consistently add one space between number and unit, for example " $2{ }^{\circ} \mathrm{C}$ ". Only $\%$ should be placed directly at the number, for example "98.3\%" DONE

5.Consistently use only SI units, for example L119 $100 \mathrm{mmol} / \mathrm{L}$ phosphate, and look for other occurrences as well. DONE

6.L124 what does "Guanine dissolved in $0.1 \mathrm{~N} \mathrm{HCl}(0.32$ umoles)" mean? a "mol" has no plural, just numbers. Replace $\mathrm{N}$ with $\mathrm{mol} / \mathrm{L}$ DONE

7.Check reference list again carefully and correct/modify according to examples as given in the instructions for authors of this journal (for example, EU regulations, ECregulations, FAO documents). Remove issue numbers in brackets, not necessary. At present, reference list is full of typos etc. NO capitals in reference text except first word. DONE

8.Figure legends should be placed on a separate page not directly at figures. There is a supplementary file in the first revision named capture list but this appears to be empty. Please place list of figure captions after the references on a separate page in the manuscript, before the tables. DONE

9.Tables: just 3 horizontal lines, one above and one below the main table body, and one separating the first parameter row from the data entries. No extra horizontal lines in the main table body. Tables 1 and 2 are ok. DONE 


\section{照 Springer}

\section{Mycotoxin Research Authorship and Disclosure Form}

Optimization and validation of a LC-HRMS method for aflatoxins determination in urine samples Article title (first few words)

First Author: Francesca Debegnach

E-mail: francesca.debegnach@iss.

After submission of this agreement signed by the corresponding author in the name of all authors, changes of authorship or in the order of the authors listed will not be accepted by Springer.

\section{AUTHORSHIP}

I, the undersigned corresponding author, certify that:

- All authors have seen and approved the final version of the manuscript, and all subsequent versions.

- All authors have made substantial contributions to conception and design, or acquisition of data, or analysis and interpretation of data;

- All authors have drafted the article or revised it critically for important intellectual content.

I accept public responsibility for it, and believe it represents valid work. As an author of this article, I also certify in the name of all authors that none of the material in the manuscript has been previously published, nor is it included in any other manuscript. I certify that this manuscript is not under consideration for publication elsewhere, nor has it been submitted or accepted in another publication in any form. The rights or interest in the manuscript have not been assigned to any third party.

Moreover, should the editor of Mycotoxin Research request the data upon which the manuscript is based, I shall produce it. I also certify that I have read and complied with the copyright information, as found on the Mycotoxin Research home page website.

\section{FINANCIAL DISCLOSURE/CONFLICTS OF INTEREST}

I certify that any financial interests such as employment, stock ownership, honoraria, paid expert testimony, as well as any personal relationships, academic competition, and intellectual passion which may inappropriately influence my actions, have been disclosed in the manuscript in the "Source of funding", "Acknowledgements" or "Conflicts of interest" section according to the instructions to authors.

I have had full access to all the data in the study (if applicable) and thereby accept full responsibility for the integrity of the data and the accuracy of the data analysis.

By checking the box next to my signature on the following page I assert that there are no conflicts of interest (both personal and institutional) regarding specific financial interests that are relevant to the work conducted or reported in this manuscript.

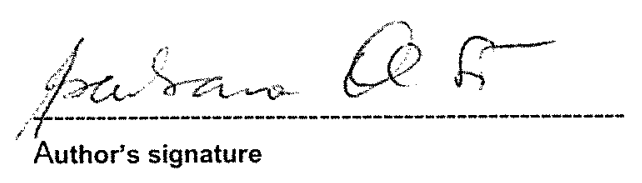

\section{Barbara De Santis}

Printed name and date

completed forms should be uploaded as a pdf file during the online submission process as a supplemental file not for review. 


\title{
Optimization and validation of a LC-HRMS method for aflatoxins
}

1

2

\section{determination in urine samples}

Francesca Debegnach ${ }^{1}$, Carlo Brera $^{1}$, Gianmarco Mazzilli ${ }^{1}$, Elisa Sonego ${ }^{1}$, Francesca Buiarelli $^{2}$, Fulvio Ferri $^{3}$, Paolo

Giorgi Rossi ${ }^{4}$, Giorgia Collini ${ }^{4}$, Barbara De Santis ${ }^{1 *}$

1 Reparto di Sicurezza Chimica degli Alimenti - Istituto Superiore di Sanità, Viale Regina Elena, 299 - 00161 Rome, Italy

2 Dipartimento di Chimica - "Sapienza" Università di Roma, Piazzale Aldo Moro, 5 - 00185 Rome, Italy

3 Servizio Prevenzione Sicurezza Ambienti di Lavoro, SPSAL - AUSL, Via Giovanni Amendola, 2 - 42122

Reggio Emilia, Italy

4 Servizio Epidemiologia, AUSL - IRCCS, Via Giovanni Amendola, 2 - 42122 Reggio Emilia, Italy

*Correspondence author: barbara.desantis@iss.it; Tel: +3906 49902367

\begin{abstract}
Mycotoxins exposure by inhalation and/or dermal contact can occur in different branches of industry especially where heavily dusty settings are present and the handling of dusty commodities is performed. This study aims to explore the possible contribution of the occupational exposure to aflatoxins by analysing urine samples for the presence of aflatoxins $\mathrm{B}_{1}$ and $\mathrm{M}_{1}$ and aflatoxin $\mathrm{B}_{1}-\mathrm{N}^{7}$-Guanine adduct. The study was conducted in 2017 on two groups of volunteers, the workers group, composed by personnel employed in an Italian feed plant ( $\mathrm{n}=32)$, and a control group $(n=29)$, composed by the administrative employees of the same feed plant; a total of 120 urine samples were collected and analysed. A screening method and a quantitative method with high resolution mass spectrometry determination were developed and fully validated. Limit of detections were 0.8 and $1.5 \mathrm{pg} / \mathrm{mL}_{\text {urine }}$ for aflatoxin $\mathrm{B}_{1}$ and $\mathrm{M}_{1}$, respectively. No quantitative determination was possible for the adduct aflatoxin $\mathrm{B}_{1}-\mathrm{N}^{7}$-Guanine. Aflatoxin $\mathrm{B}_{1}$ and its adduct were not detected in the analysed samples, aflatoxin $\mathrm{M}_{1}$, instead, was found in 14 samples (12\%) within the range $1.9-10.5 \mathrm{pg} / \mathrm{mL}_{\text {urine. }}$ Only one sample showed a value above the limit of quantification $\left(10.5 \mathrm{pg} / \mathrm{mL}_{\text {urine }}\right)$. The absence of a statistical difference between the mean values for workers and the control group were compared suggests that in this specific setting, no professional exposure occurs. Furthermore, considering the very low level of aflatoxin $\mathrm{M}_{1}$ in the collected urine samples, also the contribution from the diet to the overall exposure is to be considered negligible.
\end{abstract}




\section{Keywords}

Biomonitoring, Biomarker, Mycotoxin, Aflatoxin, Metabolites, LC-Orbitrap, LC-HRMS

\section{Introduction}

Among xenobiotics, mycotoxins, secondary metabolites of fungal origin, are the most harmful hazards with high toxic potency and recognized adverse impacts on human and animal health. More than 500 mycotoxins are known, but scientific studies focus on those that exert carcinogenic and/or toxic activity, and only few of them are regulated worldwide (Stein et al. 2017; CAST 2003; FAO 2004). Among mycotoxins, aflatoxins (AFs) represent one of the most concerning class of chemical compounds with a focus of interest on aflatoxin $\mathrm{B}_{1}\left(\mathrm{AFB}_{1}\right)$ that, due to its acute and chronic toxic effects, have raised the interest of the scientific community. The primary target organ affected by aflatoxin $\mathrm{B}_{1}$ exposure is the liver, and several epidemiological studies related $\mathrm{AFB}_{1}$ exposure to cellular hepatocarcinoma, report it as one of the major cause of cancer-related deaths in different parts of the world (Wild and Turner 2002). $\mathrm{AFB}_{1}$ is a genotoxic and carcinogenic substance, classified under group 1 by the International Agency for Research on Cancer (IARC 1993). AFs can occur in crops at pre-harvest, harvest and post-harvest stages as a result of different co-occurring environmental conditions and poor management practices (handling and storage). The expected global warming of +2 ${ }^{\circ} \mathrm{C}$ is likely to cause a sensible climate change leading to conducive environmental conditions for AFs production in Northern-Europe, where currently no occurrence is significantly present (Battilani et al. 2016). Therefore, validating new methods for AFs determination becomes particularly relevant to be applied in newly exposed geographical regions. The most common route of exposure to mycotoxins is the ingestion through the diet due to the consumption of directly or indirectly contaminated food. Furthermore, humans and animals can also be exposed to mycotoxins through inhalation and/or dermal contact with contaminated dusts (Brera et al. 2002; Doi and Uetsuka 2014; Viegas et al. 2014, 2017). Several studies reported a higher prevalence of lung carcinogenesis and bronchus and trachea tumours in workers exposed to aflatoxins contaminated dusts (McLaughlin et al. 1987; Olsen et al. 1988; Ghosh et al. 1997; SaadHussein et al. 2013, 2014), especially in branches of industry where the storage, loading, milling and handling of dusty commodities (such as grains, feed, spices, coffee, etc.) is performed. Due to their severe toxicological implications, exposure to aflatoxins must be characterized by an accurate evaluation. Commonly, two different approaches can be followed for targeting this issue: via dietary exposure assessment and/or via biomonitoring studies. The overall metabolic pathway of $\mathrm{AFB}_{1}$ is quite complex and corresponds to the formation of a number of metabolites that could be 
associated not only to the dose of the parent mycotoxin, but also to the biological response to the exposure and to the degree of individual sensitivity to adsorption and metabolism of the toxic agent (Groopman 1994). Validated exposure biomarkers for $\mathrm{AFB}_{1}$ (urinary aflatoxin $\mathrm{M}_{1}, \mathrm{AFB}_{1}-\mathrm{N}^{7}$-Guanine) were established almost 20 years ago (Groopman et al. 1993), they were critical in confirming aflatoxins as potent liver carcinogens, and more importantly, they are being used to assess the effectiveness of intervention strategies (Cramer and Uetsuka 2017; Turner et al. 2012).

Biomonitoring studies have been increased over the last 8 years. In a recent publication Viegas (Viegas et al. 2018) reviewed the use of biomonitoring in assessing occupational exposure to mycotoxin in different settings and $58 \%$ of the reviewed works assessed aflatoxins exposure. Despite the impossibility to distinguish between dietary and air-dust contamination, the literature review clearly showed that, under certain circumstances, workers were significantly more exposed than the control group (Malik et al. 2014; Saad-Hussein et al. 2014; Viegas et al. 2016). In Italy a first study on occupational exposure to aflatoxins was conducted in 2014 in two feed companies, to assess if workers occupied in dusty indoor settings were differently exposed than workers occupied in administrative units (control group) (Ferri et al. 2017). To monitor the situation and to assess the effect of new agricultural season, the same scheme of the study was replicated in 2017 within a different analytical framework, where also the guanine metabolite was included.

The present study aims to explore the role of the occupational exposure to aflatoxins by analysing urine samples to assess the presence of aflatoxins $\mathrm{B}_{1}$ and $\mathrm{M}_{1}$ and aflatoxin $\mathrm{B}_{1}-\mathrm{N}^{7}-$ Guanine adduct in a group of workers, operating in risky workplaces, and a control group. The group of volunteer workers, operating in a setting of the feed sector, potentially exposed to mycotoxins through the inhalation of contaminated dust and/or by dermal contact and a control group, composed by administrative employees working on the same feed plant, were enrolled in the study. Aflatoxins determination was performed by a high-resolution mass spectrometry (LC-HRMS) technique. For sample preparation, a dilute\&shoot method and a quantitative method based on immunoaffinity column purification step were developed and fully validated. Moreover, due to the unavailability of commercial standard of AFB $1-\mathrm{N}^{7}-\mathrm{Guanine}$, the adduct was synthetized and used for the method set up and for qualitative analysis (presence/absence) in the collected samples.

\section{Materials and Methods}

\section{Chemicals and reagents}

Chemicals and solvents used for sample preparation were LC-MS grade. Methanol, formic acid and LC-MS grade water were purchased from Fisher Scientific (Milano, Italy), $\mathrm{AFB}_{1}$ from Aspergillus flavus (purity $\geq 98 \%$ ) was from Sigma-Aldrich (Darmstadt, Germany). The analytical reference standard of $\mathrm{AFM}_{1}$ was purchased as stock solution (0.5 $\mu \mathrm{g} / \mathrm{mL}$ in acetonitrile) from Biopure ${ }^{\circledR}$ (Tulln, Austria). The isotopically labelled internal standards $\mathrm{U}_{-}\left[{ }^{13} \mathrm{C}_{17}\right]-\mathrm{AFB}_{1}$ 
$\left(99.3 \%{ }^{13} \mathrm{C}\right)$ and $\mathrm{U}-\left[{ }^{13} \mathrm{C}_{17}\right]-\mathrm{AFM}_{1}\left(98.3 \%{ }^{13} \mathrm{C}\right)$ were also purchased as acetonitrile solution $(0.5 \mu \mathrm{g} / \mathrm{mL})$ from Biopure ${ }^{\circledR}$

(Tulln, Austria). The concentration reported in the certificate accompanying the reference standard purchased as solution was considered for quantification purpose. The $\mathrm{AFB}_{1}$ powder was reconstituted with $100 \% \mathrm{ACN}$ and the concentration was assessed by molar absorbance value following the procedure reported in the official Methods of Analysis of AOAC (AOAC 2005). The $\mathrm{AFB}_{1}-\mathrm{N}^{7}$-Guanine adduct was not commercially available at the moment of the study and was synthetized as reported below.

\section{$A F B_{1}-N^{7}$-Guanine adduct synthesis and identification}

The synthesis was conducted accordingly with Vidyasagar et al. (1997) as follows: meta-chloroperoxybenzoic acid (MCPBA), $20 \mathrm{mg}$ in $4 \mathrm{~mL}$ of dichloromethane, was washed with $100 \mathrm{mM}$ mmol/L phosphate buffer, $\mathrm{pH} 7.4$ (4 mL x 4 ). The resulting MCPBA solution was passed through anhydrous sodium sulphate to remove residual water. $\mathrm{AFB}_{1}(0.64$ $\mu \mathrm{mol}$ ) was dissolved in $250 \mu \mathrm{L}$ of dichloromethane and was converted to $\mathrm{AFB}_{1}-8,9$-epoxide by addition of $250 \mu \mathrm{L}$ of the above MCPBA solution ( $4 \mu \mathrm{mol})$ and $500 \mu \mathrm{L}$ of $100 \mathrm{mM} \mathrm{mmol} / \mathrm{L}$ phosphate buffer, $\mathrm{pH}$ 7.2. The reaction was carried out at $5{ }^{\circ} \mathrm{C}$ for 100 min with continuous vigorous stirring. At the end of 100 min the buffer fraction was pipetted out. $0.32 \mu \mathrm{mol}$ of Guanine, previously dissolved in $0.1 \mathrm{~mol} / \mathrm{L} \mathrm{HCl}$, were added to $500 \mu \mathrm{L}$ of $100 \mathrm{mM} \mathrm{mmol} / \mathrm{L}$ phosphate buffer, pH 7.4 (maximum solubility of guanine in phosphate buffer was found to be $140 \mu \mathrm{g} / \mathrm{mL}$ ). The buffer with guanine was added to the tube containing $\mathrm{AFB}_{1}-8,9$-epoxide in dichloromethane and the reaction was continued for $60 \mathrm{~min}$ at $5{ }^{\circ} \mathrm{C}$ with continuous vigorous stirring. At the end of $60 \mathrm{~min}$ the reaction mixture was centrifuged at 4000 rpm for 5 min. The organic phase was separated and the buffer fraction was repeatedly washed with dichloromethane (500 $\mu \mathrm{L} \times 3$ times). The adduct identification was based on the observation of the molecular ion and at least one fragment specific for the analyte after injection in the LC-HRMS system, according to the guidance document on identification of mycotoxins in food and feed (EC 2016). Due to the difficulties in assessing the concentration level of the synthetized adduct, the diluted buffer fraction was used for testing the IAC cross reactivity during method development and for a qualitative evaluation of presence/absence in the collected urine samples.

\section{Study design}

The investigation was conducted in the same feedstuff plant involved in the first study previously published by Ferri et al. (2017). This second study was conducted within the framework of a larger project entitled "Biomonitoring data as a tool for assessing aflatoxin $B_{1}$ exposure of workers - BIODAF” supported by EFSA (July 2017 - June 2018). The project focused on aflatoxins and took into consideration urine and serum samples collection and analysis. Two 
9

countries, Italy and Portugal, were involved in this study. The present paper reports the results obtained from the Italian urine analyses.

Two groups of volunteers were enrolled, the "workers group", corresponding to all workers in direct contact with some risky activities such as the downloading of the raw material, its handling and the cleaning procedures; and the "control group", which included employees of the same company but designated to perform other activities considered not risky for the absence of contaminated environmental dusts. The samples were collected on Monday and Friday morning in one working week, Monday was chosen since it reflects a situation characterized by a preceding two-days washing period and Friday was selected with the aim to verify a possible accumulation of AFs and consequent intake over the week of sampling. The urine was collected in the morning and delivered to the medical staff before starting the morning shift. A total of 61 male volunteers were enrolled ( 32 workers and 29 controls). The collected urine samples were stored at $-20{ }^{\circ} \mathrm{C}$ until analysis. The mean value and range for age and body weight of the enrolled volunteers are reported in Table 1.

The study was conducted under the supervision of the Local Health Unit of Reggio Emilia and was approved by the Ethical Committee of the Reggio Emilia province. All urine donors were informed about the purpose of the study and a formal consent was individually signed prior to inclusion in the study.

\section{Sample preparation}

Dilute\&shoot sample preparation

Before analysis, all urine samples were equilibrated to room temperature and homogenized by shaking thoroughly. Aliquots of $100 \mu \mathrm{L}$ urine were mixed with $860 \mu \mathrm{L}$ of $\mathrm{H}_{2} \mathrm{O}$ LC-MS grade; for quantification purpose $20 \mu \mathrm{L}$ of $\mathrm{U}_{-}\left[{ }^{13} \mathrm{C}_{17}\right]$ $\mathrm{AFB}_{1} 5 \mathrm{ng} / \mathrm{mL}$ in acetonitrile and $20 \mu \mathrm{L}$ of $\mathrm{U}-\left[{ }^{13} \mathrm{C}_{17}\right]-\mathrm{AFM}_{1} 10 \mathrm{ng} / \mathrm{mL}$ in acetonitrile were added to the sample. The diluted sample was centrifuged for 10 minutes at $3500 \mathrm{xg}(\mathrm{RCF})$ before the injection of $10 \mu \mathrm{L}$ into the UHPLC-HRMS system.

\section{Immunoaffinity clean-up}

Before analysis, all urine samples were equilibrated to room temperature and homogenized by shaking thoroughly. Aliquots of $2 \mathrm{~mL}$ urine were mixed with $10 \mathrm{~mL}$ of phosphate buffered solution (PBS, pH=7.4) and passed through the immunoaffinity column (IAC) for purification (Easy-extract ${ }^{\circledR}$ aflatoxins, from R-Biopharm, Darmstadt, Germany). The IAC was washed with $30 \mathrm{~mL}$ of $\mathrm{H}_{2} \mathrm{O}(10+10+10 \mathrm{~mL})$, then the toxins were eluted with $1 \mathrm{~mL}$ of $\mathrm{MeOH}(500+500 \mu \mathrm{L})$. Finally, $500 \mu \mathrm{L}$ of eluted sample were added with $20 \mu \mathrm{L} \mathrm{U}-\left[{ }^{13} \mathrm{C}_{17}\right]-\mathrm{AFB}_{1} 2.5 \mathrm{ng} / \mathrm{mL}$ in $\mathrm{ACN}, 20 \mu \mathrm{L} \mathrm{U}-\left[{ }^{13} \mathrm{C}_{17}\right]-\mathrm{AFM}_{1} 5$ $\mathrm{ng} / \mathrm{mL}$ in ACN and $460 \mu \mathrm{L}$ of $\mathrm{H}_{2} \mathrm{O}$. A volume of $20 \mu \mathrm{L}$ was injected into the UHPLC-HRMS system. 


\section{Analytical quantification}

For mycotoxins quantification an internal standard (ISTD) approach was adopted. The internal standard for $\mathrm{AFB}_{1}$ and $\mathrm{AFM}_{1}$ was the ${ }^{13} \mathrm{C}$ isotope labelled molecule in which all carbon atoms are substituted by the stable isotope ${ }^{13} \mathrm{C}$. Six points calibration curve was obtained by plotting the response ratio (standard area/ ${ }^{13} \mathrm{C}$ area) versus the concentration

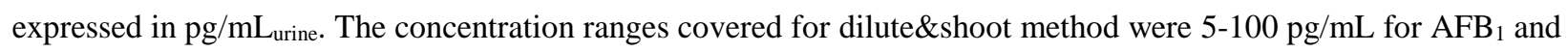
10-200 pg/mL for $\mathrm{AFM}_{1}$, corresponding to 50-1000 pg/mL urine and 100-2000 pg/mL urine for $\mathrm{AFB}_{1}$ and $\mathrm{AFM}_{1}$, respectively. For IAC method the ranges were 5-50 pg/mL for $\mathrm{AFB}_{1}$ and $10-100 \mathrm{pg} / \mathrm{mL}$ for $\mathrm{AFM}_{1}$, corresponding to

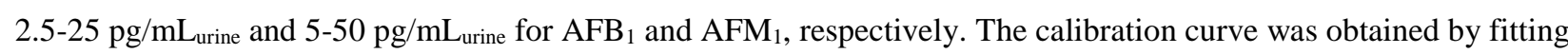
the data with a linear regression model based on least squares method.

\section{Validation criteria}

Identification criteria were set for all the analysed mycotoxins. Linearity and limit of detection (LOD) and quantification (LOQ) of the analytical methods were assessed. Precision and trueness were assessed from repeated 
analyses on spiked blank urine samples. Precision was evaluated by calculating the intermediate relative standard deviation (repeated analyses on different days), while trueness was estimated in terms of apparent recovery $\left(\mathrm{R}_{\mathrm{A}}\right)$. Extraction efficiency $\left(\mathrm{R}_{\mathrm{E}}\right)$ and matrix effect (SSE) were also evaluated for validation purpose.

\section{Method validation}

For both methods, linearity of the method was evaluated from six points calibration curves injected in triplicate for three consecutive days. Regression lines were plotted applying a linear regression model based on least squares method. The linearity was assessed by visual checking of the residual plot of response ratios (plotted in y-direction) versus the respective concentration levels (plotted in $\mathrm{x}$-direction). The final estimated linearity model was verified using the lackof-fit test (significance of the test with $\mathrm{p}_{\text {value }}$ below 0.05 ), to confirm that the selected regression and linearity were acceptable. Once visual checking of the residual and lack-of-fit test passed, the R squared coefficient was taken as a measure of linearity.

According to the criteria reported in the SANTE/12089/2016 guidance document on identification of mycotoxins in food and feed (EC 2016), the retention time (RT) of the analyte in the sample extract should correspond to that of the average of the calibration standards measured in the same sequence with a tolerance of $\pm 0.1 \mathrm{~min}$. Moreover, for the ISTD added to the sample extract, the RT of the analyte should correspond to that of its labelled ISTD with a tolerance of $\pm 0.05 \mathrm{~min}$. For HRMS analysis identification is based on observation of the molecular ion (or, if not available, adducts) and one fragment that is specific for the selected analyte.

According to Wenzl et al. (2016), spiked blanks approach was used for LOD and LOQ assessment, by analysing the spiked sample in ten replicates under repeatability conditions. The variability expressed as standard deviation obtained for the ten analyses of spiked blanks was used for the estimation of the critical value of LOD. Calculations were carried out according to Equation 1 and 2.

$$
\begin{aligned}
& x_{L O D}=3.9 \times \frac{s_{y, b}}{b} \\
& x_{L O Q}=3.3 \times x_{L O D}
\end{aligned}
$$

The LOQ values obtained with the theoretical calculation approaches were included in the validation as the lowest concentration level.

For dilute\&shoot method, the matrix effect was examined according to Sulyok et al. (2006) assessing the matrix induced enhancement or suppression during analysis. For this purpose, calibration curves in solvent ( 5 calibration points in the range of $40-200 \mathrm{pg} / \mathrm{mL}$ for $\mathrm{AFB}_{1}$ and $80-400 \mathrm{pg} / \mathrm{mL}$ for $\mathrm{AFM}_{1}$, constructed by plotting signal intensity versus the 
analyte concentration) were compared with matrix-matched calibration curves (blank sample 1:10 diluted spiked at 5 levels, curves obtained by plotting the signal intensity against the actual spiking level). The slopes of the resulting calibration curves were used for signal suppression/enhancement (SSE) calculation (Equation 3).

$\operatorname{SSE}(\%)=100 * \frac{\text { slope }(\text { matrix }- \text { matched standard })}{\text { slope }(\text { solvent standard })}$

For IAC method, apparent recovery, matrix effect and extraction recovery were assessed on 5 different levels of contamination, including the calculated LOQ values, for each level triplicate analyses of spiked blank sample on 2 consecutive days were performed. The obtained data were used for apparent recovery $\left(\mathrm{R}_{\mathrm{A}}\right)$, matrix effect and extraction recovery $\left(\mathrm{R}_{\mathrm{E}}\right)$ calculations and for precision assessment. The $\mathrm{R}_{\mathrm{A}}$ is calculated as the ratio between the slope of the spiked sample curve, obtained from the spiked samples, and the slope of the calibration curve in pure solvent (Equation 4). In this case, the curves were obtained considering the area and not the ratio with the labelled internal standard added for each mycotoxin. The $\mathrm{R}_{\mathrm{A}}$ represents the influence of the whole analytical process (sample preparation + determination) on the signal and it is also referred to as overall or total recovery of a method. $\mathrm{R}_{\mathrm{A}}$ was the parameter used for trueness evaluation.

$\mathrm{R}_{\mathrm{A}}(\%)=100 * \frac{\text { slope }(\text { spiked sample })}{\text { slope }(\text { solvent standard })}$

The matrix effect was evaluated in terms of Signal Suppression/Enhancement (SSE) and it was calculated, according to Equation 5, as the ratio between the mean area of the labelled ISTD in the spiked sample extract and in the pure solvent standard solution.

$\operatorname{SSE}(\%)=100 \times \frac{\text { area } U-\left[13 C_{17}\right]-A F B_{1} \text { sample }}{\text { area } U-\left[13 C_{17}\right]-A F B_{1} \text { standard }}$

The $\mathrm{R}_{\mathrm{E}}$, accounting to incomplete extraction of the analyte from the matrix, was calculated from $\mathrm{R}_{\mathrm{A}}$ and SSE, according to Equation 6.

$\mathrm{R}_{\mathrm{E}}(\%)=100 * \frac{\mathrm{R}_{\mathrm{A}}}{\mathrm{SSE}}$ 
The effect of random errors on the measurements were assessed and quantified as the relative standard deviation (RSD) of repeated independent analyses conducted in intermediate conditions of repeatability within the laboratory ( $\left.\mathrm{RSD}_{\mathrm{LR}}\right)$. Instrumental laboratory reproducibility of the LC-HRMS system was also evaluated by injecting on three consecutive days (inter-run) and in replicates (intra-run) a neat solvent standard solution ( $\mathrm{AFB}_{1} 150 \mathrm{pg} / \mathrm{mL}$ and $\mathrm{AFM}_{1} 300 \mathrm{pg} / \mathrm{mL}$ ). Moreover, the intermediate precision of the whole method was evaluated by analyzing daily independent urine sample spiked at the same contamination level as an internal control sample (inter-day). The performance criteria for precision, quantified with standard deviation of repeatability within the laboratory $\left(\mathrm{s}_{\mathrm{LR}}\right)$ and expressed in percentage as $\mathrm{RSD}_{\mathrm{LR}}$, was set at $15 \%$ of variability, including any source of instrumental and analytical possible random errors. Precision was estimated in terms of intermediate precision $\mathrm{RSD}_{\mathrm{LR}}$ of repeatability.

\section{Results and Discussion}

\section{Sample preparation and LC-HRMS analysis}

During method set up two urine:water dilution factors, namely 1:5 and 1:10, were tested for dilute\&shoot approach. The 1:10 dilution gave better results in terms of SSE and was selected for the analysis. The IAC purification step was introduced in order to reduce the LOD/LOQ values. The employed IAC contains specific antibodies to aflatoxins $\mathrm{B}_{1}$, $B_{2}, G_{1}, G_{2}$ and $M_{1}$, no specific information was given by the supplier for $A F B_{1}-N^{7}$-Guanine. To evaluate the risk of adduct loss during purification, the synthetized adduct was applied to the IAC, eluted according to method protocol and the presence of the adduct was confirmed by LC-HRMS identification.

HRMS conditions were set by direct infusion of standard solution for $\mathrm{AFB}_{1}$ and $\mathrm{AFM}_{1}$, while for $\mathrm{AFB}_{1}-\mathrm{N}^{7}$-Guanine the selection of collision energy and specific fragments were guided by the work of Walton et al. (2001). $\mathrm{AFB}_{1}$ produces sodiated adduct in a non negligible amount when compared with protonated adduct during electrospray ionization step, although $\mathrm{AFB}_{1}$ is unlikely produce ammonium adduct, the presence of the ammonium in the mobile phase suppresses the sodiated adduct in favour of the protonated one. This is the reason for the presence in the mobile phases of formic acid and ammonium formate. For quantitative purpose the protonated adducts were selected, for $\mathrm{AFM}_{1}$, since it was not possible to reduce the sodiated adduct production by varying source parameters, the sum of the protonated and sodiated adduct was considered.

\section{Validation parameters}

Linearity was checked in the working range by the lack-of-fit test based on the analysis of variance (F test with $p$ value $<0.05$ ) and the plot of the residual values randomly distributed around zero, confirming the linearity. During routine analytical sessions an $\mathrm{R}^{2}>0.990$ was set as a criterion for calibration curve acceptability. In Table 3 the calibration 
curve ranges, the amount of ISTD added to each calibration level and the correlation coefficients $\left(\mathrm{R}^{2}\right)$ obtained for each mycotoxin/matrix combination are reported.

The performance characteristics, in terms of $\mathrm{R}_{\mathrm{A}}, \mathrm{SSE}$ and $\mathrm{R}_{\mathrm{E}}$, are summarized in Table 4 together with LOD and LOQ values and the working range of the two analytical procedures. Both methods may be applied for quantitative analysis of $\mathrm{AFB}_{1}$ and $\mathrm{AFM}_{1}$ as well as for the evaluation of presence/absence of the $\mathrm{AFB}_{1}-\mathrm{N}^{7}$-Guanine adduct. The dilute\&shoot method is characterized by higher LOD and LOQ values when compared with the IAC clean-up method, but on the other hand the dilute\&shoot approach is very quick and characterized by a conservative approach with respect to the sample, giving the possibility of a retrospective analysis on the acquired data. Due to the absence of a sample pre-

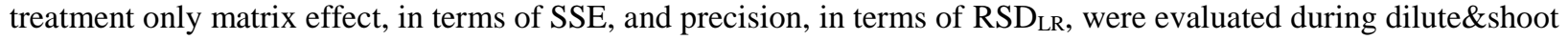
method validation. SSE percentages are very close to $100 \%$ due to the dilution applied to the urine sample; method precision was assessed by performing 8 independent analyses at the LOQ level. The IAC clean-up method was fully validated, trueness was evaluated in terms of apparent recovery $\left(\mathrm{R}_{\mathrm{A}}\right)$ while precision was assessed by laboratory reproducibility $\mathrm{RSD}_{\mathrm{LR}}$ measures. Although the IAC clean-up, which is a very selective approach, was used, the influence of the matrix was also evaluated, and the percentages of SSE for $\mathrm{AFB}_{1}$ and $\mathrm{AFM}_{1}$ found confirmed that the influence of the matrix on the instrumental response is very limited.

LOD and LOQ of analytical methods always represent a challenge being the bottleneck for the reliability of the analytical results and also for the further processing of the findings (i.e. data mining). Modern HRMS instruments makes it possible to reach high sensitivities with low detection limits, and especially when methods are targeted, good benchmarks can be achieved. Among the most recent studies on the biomonitoring of aflatoxins, the lowest values for $\mathrm{AFM}_{1}$ were found in the range of $0.13-0.6 \mathrm{pg} / \mathrm{mL}_{\text {urine }}$ and in the $0.4-1.8 \mathrm{pg} / \mathrm{mL}_{\text {urine }}$ for LOD and LOQ, respectively (Giolo et al. 2012; Romero et al. 2010). Although these values represent a gold standard benchmark, they are not covered by the strict performance requirements of accuracy, which instead were met at $10 \mathrm{pg} / \mathrm{mL}_{\text {urine }}(\mathrm{Giolo}$ et al. 2012) and $4 \mathrm{pg} / \mathrm{mL}_{\text {urine }}$ (Romero et al. 2010). Thus, the LOD/LOQ values obtained in the IAC method, validated under strict performances, are in alignment with the findings in other bomonitoring works for $\mathrm{AFM}_{1}$. Notwithstanding, all the positive samples were in the range of values between LOD and LOQ, revealing the crucial need to stress the method to reach lower levels. In conclusion, the general validation results obtained in this study are considered satisfactory either for screening and for confirmation and the method is considered to suit for the production accurate data for biomonitoring purposes.

\section{Analytical results}

Statistical analysis and Data handling - Left censored data 
The hypothesis of normal distribution (Shapiro-Wilk test) was refused, thus non-parametrical tests were used for the statistical treatment of the analytical results. All possible differences between concentration levels of mycotoxins in exposed and non-exposed groups were explored by a Wilcoxon rank-sum test. To assess the correlation between mycotoxin levels, a Spearman's rank correlation coefficient (or Spearman's rho) was used. All tests were conducted with a level of significance of 5\%. Analyses were conducted by means of STATA14 software (Stata/IC 14.0, Copyright 1985-2015 StataCorp LP). Under the rigid identification criteria for analyte determination, namely the RT criteria ( $\mathrm{RT} \pm 0.1 \mathrm{~min}$ with respect to the standard $\mathrm{RT}$ ) and the presence of the precursor ion and at least one characteristic fragment for each considered analyte, it was decided to include and report also all the values below LOQ obtained by the interpolation of the calibration curve. Thus, values lower than LOQ were reported in the dataset as positive samples provided that the identification criteria were met. The results evaluation included also the reporting of the lower and upper bound (LB and UB) mean values (EFSA 2010). These values were calculated applying a substitution method for which in the LB calculations the results lower than LOQ were substituted with zero, while in the UB the results lower than LOQ were substituted with LOQ value depending on the method.

\section{Analysis of samples}

The collected urine samples were analysed first with the dilute\&shoot method, through which none of the sample showed a measurable level of $\mathrm{AFB}_{1}$ or $\mathrm{AFM}_{1}$, including $\mathrm{AFB}_{1}-\mathrm{N}^{7}$-Guanine which was not detected. To overcome the limitations coming from the detection limit threshold of the dilute\&shoot method and verify that the negativity of the results could be caused by the level of LOD/LOQ declared, it was decided to set up and validate a method with lower LOQ. A purification step was introduced using an IAC clean-up to clean and concentrate the urine sample. By using this method for reprocessing the urine samples, $\mathrm{AFB}_{1}$ and its adduct were not detected, $\mathrm{AFM}_{1}$, instead, was found in 14 samples (12\%) within the range 1.9-10.5 pg/mLurine. Only one sample, coming from the workers' group, showed a value above the LOQ $\left(10.5 \mathrm{pg} / \mathrm{mL}_{\text {urine }}\right)$ and it is a sample from the workers group. Tables 5 and 6 summarize the percentages of positive samples, maximum values found, and mean values (LB-UB) for worker and control groups, respectively. It should be noted that when values reported for $\mathrm{AFM}_{1}$ are below the LOQ they were considered as affected by a standard uncertainty higher than $25 \%$, which was the performance criteria set for maximum standard uncertainty for the LOQ. The LB-UB values reflect the optimistic and pessimistic scenario range of possible mean values. Figure 1 shows the data trend for $\mathrm{AFM}_{1}$ in urine for both groups, Monday and Friday sampling. On the left side LB substitution method was applied, due to the high number of non-detected (87\%), box plot is flattened to zero. On the right side the box plot reports all the positive values are reported. The band inside the box is the second quartile (P50, 
median). Dots indicates suspected outliers. Whiskers are set from minimum to maximum value. First and third quartiles (P25 and P75) can be found at the bottom and the top of the box, respectively.

No statistical difference for $\mathrm{AFM}_{1}$ was observed between Monday and Friday samples in each group (exposed and nonexposed workers). To note that among the positive results two individuals of the exposed workers group showed AFM 1 in both Monday and Friday deliveries $\left(3.3\right.$ and $3.0 \mathrm{pg} / \mathrm{mL}_{\text {urine }}$ and 4.6 and $10.5 \mathrm{pg} / \mathrm{mL}_{\text {urine }}$, Monday and Friday values for each individual, respectively. Further statistical analyses were performed merging data of Monday and Friday data (63 analyses for exposed workers group and 57 for non-exposed workers group). Eight samples (13\%) resulted positive in the workers' group where the highest contaminated sample was found $\left(10.5 \mathrm{pg} / \mathrm{mL}_{\text {urine }}\right)$; six samples (11\%) were positive in the control group, the higher detected value was $4.1 \mathrm{pg} / \mathrm{mL}$ urine. In order to find differences among the positive values found in workers and control group, a Wilcoxon rank-sum test was performed but no statistical significances were highlighted; even exploring the two days of urine delivery, no differences were highlighted. The absence of $\mathrm{AFB}_{1}$ and its adduct, together with the absence of a statistical difference when the mean values of $\mathrm{AFM}_{1}$ for workers and control groups were compared, suggests that in this specific setting, no professional exposure occurs. Moreover, considering the very low level of $\mathrm{AFM}_{1}$ in the collected urine samples, also the contribution from the diet to the overall exposure is to be considered negligible.

This study presents a method, performed by a high-resolution mass spectrometry (LC-HRMS) technique, to detect $\mathrm{AFB}_{1}$ and aflatoxin biomarkers, namely $\mathrm{AFM}_{1}$ and aflatoxin-N7-Guanine. If compared with the previous study conducted in 2014 (Ferri et al. 2017), the present work tackles with an improvement of method sensitivity (1.5 $\mathrm{pg} / \mathrm{mL}_{\text {urine }}$ versus $25 \mathrm{pg} / \mathrm{mL}_{\text {urine }}$ in Ferri et al. (2017). High percentages of workers positive for $\mathrm{AFB}_{1}$ were reported in several studies conducted in EU (Portugal, Italy, Denmark) (Olsen et al. 1988; Viegas et al. 2018; Ferri et al. 2017) emphasizing that occupational exposure might be critical in certain settings, such as feed plants, in which indoor areas can be conducive of highly contaminated dust particles. In this study, morning urine samples were collected during one working week from a cohort of occupational exposed workers of a feed company and from a control group. The presence of only one positive sample of $\mathrm{AFB}_{1}$ and the lack of statistical difference between mean values of $\mathrm{AFM}_{1}$ in workers and control groups, suggests that in this specific setting, the primary route of exposure to AFs is more likely to be attributed to the diet and not to the respiratory route when inhalation or dermal contact of aerosolized contaminated dusts occur. However, the attention and focus to AFs can't never be reduced to a no-risk situation, since, due to the direct correlation between aflatoxins occurrence and climate changes, a systematic monitoring of the health status of citizen (including workers) potentially exposed to dusts contaminated by these toxic compounds, has to be duly undertaken. 


\section{Compliance with ethical standard}

The study has been approved by the Ethical Committee of Reggio Emilia Province and performed in accordance with the ethical standards laid down in the 1964 Declaration of Helsinki and its later amendments.

Conflict of Interest The authors declare no conflict of interest.

\section{Acknowledgements}

This research was funded by EFSA: GP/EFSA/AFSCO/2017/05PERFORMANCE: International Conference "The Burden of Mycotoxins on animal and human health" and Research Project "Biomonitoring data as a tool for assessing aflatoxin $\mathrm{B}_{1}$ exposure of workers - BIODAF". Sole responsibility lies with the author and the Authority is not responsible for any use that may be made of the information contained therein.

Gabriele Moracci, Paola De Santis, Maria Cristina Barea Toscan and Giuliana Verrone (Istituto Superiore di Sanità), and Massimo Magnani (Servizio Prevenzione Sicurezza Ambienti di Lavoro) are acknowledged for their technical assistance.

\section{References}

AOAC - Association of Official Agricultural Chemists (2005) Official methods of analysis of AOAC international, Ch.49.2.02 Method, 970.44

Battilani P, Toscano P, Van der Fels-Klerx HJ, Moretti A, Camardo Leggieri M, Brera C, Rortais A, Goumperis T, Robinson T (2016) Aflatoxin $B_{1}$ contamination in maize in Europe increases due to climate change. Sci Rep https://doi.org/10.1038/srep24328

Brera C, Caputi R, Miraglia M, Iavicoli I, Salerno A, Carelli G (2002) Exposure assessment to mycotoxins in workplaces: aflatoxins and ochratoxin A occurrence in airborne dusts and human sera. Microchem J 73:167-173.

CAST - Council for Agricultural Science and Technology (2003) Mycotoxins: risks in plant, animal and human systems. Task force report No 139.

Cramer B, Humpf H (2017) Human biomonitoring of mycotoxins for the detection of nutritional, environmental and occupational exposure. In: Viegas C, Viegas S, Gomes A, Täubel M, Sabino R (eds) Exposure to microbiological agents in indoor and occupational environments. Springer, Cham, pp 191-212. https://doi.org/10.1007/978-3-31961688-9_9 
Doi K, Uetsuka K (2014) Mechanisms of mycotoxin-induced dermal toxicity and tumorigenesis through oxidative stress-related pathways. J Toxicol Pathol 27:1-10. https://doi.org/10.1293/tox.2013-0062

EFSA - European Food Safety Authority (2010) Management of left-censored data in dietary exposure assessment of chemical substances. EFSA J 8:1557. Available from: https://doi.org/10.2903/j.efsa.2010.1557

European Commission [EC] (2016) Guidance document on identification of mycotoxins in food and feed.

SANTE/12089/2016. Available from: http://tinyurl.com/y86zckkj

FAO - Food and Agriculture Organization of the United Nations (2004) Worldwide regulations for mycotoxins in food and feed in 2003. FAO Food and Nutrition Paper 81. Rome, Italy. Available from:

http://www.fao.org/3/y5499e/y5499e00.htm\#Contents

Ferri F, Brera C, De Santis B, Fedrizzi G, Bacci T, Bedogni L, Capanni S, Collini G, Crespi E, Debegnach F, Ferdenzi P, Gargano A, Gattei D, Luberto F, Magnani I, Magnani MG, Mancuso P, Menotta S, Mozzanica S, Olmi M, Ombrini G, Sala O, Soricelli S, Vicentini M, Giorgi Rossi P (2017) Survey on urinary levels of Aflatoxins in professionally exposed workers. Toxins 9:117. https://doi.org/10.3390/toxins9040117

Ghosh SK, Desai MR, Pandya GL and Venkaiah K (1997) Airborne aflatoxin in the grain processing industries in India. Am Ind Hyg Assoc J 58:583-586

Giolo MP, de Oliveira CM, Bertolini DA, Campana Lonardoni MV, Gouveia MS, Pontes Netto D, Nixdorf SL, Machinski M (2012) Aflatoxin M1 in the urine of non-carriers and chronic carriers of hepatitis B virus in Maringa, Brazil. Braz J Pharm Sci 48:447-451. http://dx.doi.org/10.1590/S1984-82502012000300011

Groopman JD (1994). Molecular dosimetry methods for assessing human aflatoxin exposures. In: Eaton DL, Groopman JD (eds) The toxicology of aflatoxins: human health, veterinary, and agricultural significance. Academic Press CA, San Diego, pp 259-280

Groopman JD, Wild CP, Hasler J, Junshi C, Wogan GN, Kensler TW (1993) Molecular epidemiology of aflatoxin exposures: validation of aflatoxin-N7-guanine levels in urine as a biomarker in experimental rat models and humans. Environ Health Perspect 99:107-113. https://doi.org/10.1289/ehp.9399107 International Agency for Research on Cancer [IARC] (1993) Some naturally occurring substances: food items and constituents, heterocyclic aromatic amines and mycotoxins, Vol. 56: IARC Monographs on the evaluation of the carcinogenic risks to humans, pp. 1-599. Available from: https://publications.iarc.fr/Book-And-Report-Series/IarcMonographs-On-The-Identification-Of-Carcinogenic-Hazards-To-Humans/Some-Naturally-Occurring-SubstancesFood-Items-And-Constituents-Heterocyclic-Aromatic-Amines-And-Mycotoxins-1993 
Malik A, Ali S, Shahid M Bhargava R (2014) Occupational exposure to Aspergillus and aflatoxins among food-grain workers in India. Int J Occup Environ Health 20:189-193

McLaughlin JK, Malker HSR, Malker BK, Stone BJ, Ericsson JLE, Blot WJ, Weiner JA, Fraumeni JF (1987) Registrybased analysis of occupational risks for primary liver cancer in sweden. Cancer Res 47:287-291

Olsen JH, Dragsted L, Autrup H (1988) Cancer risk and occupational exposure to aflatoxins in Denmark. Br J Cancer 58:392-396

Romero AC, Ferreira TRB, Dias CTS, Calori-Domingues MA, Gloria EM (2010) Occurrence of AFM1 in urine samples of a Brazilian population and association with food consumption. Food Control 21:554-558

Saad-Hussein A, Beshir S, Moubarz G, Elserougy S and Ibrahim MI (2013) Effect of exposure to aflatoxins on some liver tumor markers in textile workers. Am J Ind Med 56:818-824

Saad-Hussein A, Taha MM, Beshir S, Shahy EM, Shaheen W, Elhamshary M (2014) Carcinogenic effects of aflatoxin B1 among wheat handlers. Int J Occup Environ Health 20:215-219

Stein RA, Bulboaca AE (2017) Mycotoxins. In: Dodd C, Aldsworth T, Stein R (eds) Foodborne Diseases, 3rd edn. Elsevier, San Diego, United States, pp 407-446

Sulyok M, Berthiller F, Krska R, Schuhmacher R (2006) Development and validation of a liquid chromatography/tandem mass spectrometric method for the determination of 39 mycotoxins in wheat and maize. Rapid Commun Mass Spectrom 20:2649-2659. https://doi.org/10.1002/rcm.2640

Turner P, Flannery B, Isitt C, Ali M, Pestka J (2012) The role of biomarkers in evaluating human health concerns from fungal contaminants in food. Nutr Res Rev 25:162-179. https://doi.org/10.1017/S095442241200008X

Vidyasagar T, Sujatha N, Sashidhar RB (1997) Direct synthesis of aflatoxin $\mathrm{B}_{1}-\mathrm{N}^{7}$-Guanine adduct: a reference standard for biological monitoring of dietary aflatoxin exposure in molecular epidemiological studies. Food Add Contam 14:457-467. https://doi.org/10.1080/02652039709374552

Viegas S, Osteresch B, Hövelmann Y, Cebola de Oliveira A, Cramer B, Viegas C, Humpf HU (2017) Exposure to mycotoxins in Cork industry - The importance of a multibiomarker approach. $10^{\text {th }}$ International Symposium on Biological Monitoring in Occupational and Environmental Health. Naples, Italy Viegas S, Veiga L, Almeida A, dos Santos M, Carolino E and Viegas C (2016) Occupational exposure to aflatoxin B1 in a Portuguese poultry slaughterhouse. Ann Occup Hyg 60:176-183

Viegas S, Veiga L, Figueiredo P, Almeida A, Carolino E, and Viegas C (2014) Assessment of workers' exposure to Aflatoxin $\mathrm{B}_{1}$ in a Portuguese waste industry. Ann Occup Hyg 59:173-181.

https://doi.org/10.1093/annhyg/meu082Viegas S, Viegas C, Oppliger A (2018) Occupational exposure to mycotoxins: current knowledge and prospects. Ann Work Expo Health 62:923-941. doi: 10.1093/annweh/wxy070 
456 Walton M, Egner P, Scholl PF, Walker J, Kensler TW, Groopman JD (2001) Liquid chromatography electrospray-mass $\frac{1}{45}$ spectrometry of urinary aflatoxin biomarkers: characterization and application to dosimetry and chemoprevention in 3 458

5 Wenzl T, Haedrich J, Schaechtele A, Robouch P, Stroka J (2016) Guidance Document on the Estimation of LOD and rats. Chem Res Toxicol 14:919-926 7 460 9 14661

European Union, Luxembourg. https://doi.org/10.2787/8931

Wild CP, Turner PC (2002) The toxicology of aflatoxins as a basis for public health decisions. Mutagenesis 17:471481. https://doi.org/10.1093/mutage/17.6.471 
486 Figure 1 Data trend for AFM1 in urine for exposed and control groups. Left side, mean LB values; right side, mean 1 48 positive values. The horizontal band (inside the box) is the second quartile (P50, median). Dots are suspected outliers. 3 488 5 489 (P25 and P75).

7 490 9 1691 11 1492 
517

1

2

3

4

5

7

5818

9

15019

11

1520

13

1521

15

15522

17

15323

19

2524

21

2325

23

2326

25

2ु5 7

27

23. 8

29

339

31

3330

33

3431

36

372

383

40,4

41

425

446

46
47
47

48

50

519

52

5340

54

554

56
5542

58

5993

60

6544

62

63

64

65

\begin{tabular}{lccc}
\hline Volunteers & Number of subjects & Mean age (range); years & Mean body weight (range); kg \\
\hline Workers group & 32 & $53(32-65)$ & $80.1(62-99)$ \\
Controls group & 29 & $48(33-63)$ & $83.4(64-125)$ \\
Total & 61 & - & - \\
\hline
\end{tabular}

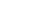

Table 1. Distribution of the enrolled volunteers by group, age and body weight

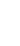


Table 2 Precursor ion, fragments and collision energy used for the detection of the selected mycotoxins in urine samples

\begin{tabular}{lcccc}
\hline Compound & Chemical formula & Precursor ion $(\mathbf{m} / \mathbf{z})[\mathbf{M + H}]^{+}$ & Fragment $(\mathbf{m} / \mathbf{z})$ & NCE $^{\mathrm{a}}$ \\
\hline $\mathrm{AFB}_{1}$ & $\mathrm{C}_{17} \mathrm{H}_{12} \mathrm{O}_{6}$ & 313.07066 & $285.07571 ; 241.04952$ & 25 \\
${ }^{13} \mathrm{C}_{17}-\mathrm{AFB} 1$ & $\mathrm{C}_{17} \mathrm{H}_{12} \mathrm{O}_{6}$ & 330.12770 & - & - \\
$\mathrm{AFM}_{1}$ & $\mathrm{C}_{17} \mathrm{H}_{12} \mathrm{O}_{7}$ & $329.06558+351.04752^{\mathrm{b}}$ & $273.07538 ; 229.04937$ & 27 \\
${ }^{13} \mathrm{C}_{17}-\mathrm{AFM}$ & $\mathrm{C}_{17} \mathrm{H}_{12} \mathrm{O}_{6}$ & $346.12261+368.10456^{\mathrm{b}}$ & - & - \\
$\mathrm{AFB}_{1}-\mathrm{N}^{7}$-Guanine & $\mathrm{C}_{22} \mathrm{H}_{17} \mathrm{~N}_{5} \mathrm{O}_{8}$ & 480.11499 & $152.05678,165.05499$ & $40 ; 90$ \\
\hline malised Collision Energy; ${ }^{\mathrm{b}}[\mathrm{M}+\mathrm{Na}]^{+}$ & & &
\end{tabular}

${ }^{\mathrm{a}}$ Normalised Collision Energy; ${ }^{\mathrm{b}}[\mathrm{M}+\mathrm{Na}]^{+}$ 
450

46

47

492

51.

53.

54

55

5595

57

5896

59

697

61

62

63

64

65
Table 3 Calibration curve range, labelled internal standard concentration and correlation coefficients obtained for each mycotoxin/matrix combination are reported

\begin{tabular}{|c|c|c|c|c|c|c|}
\hline \multirow[t]{2}{*}{ Method } & \multicolumn{2}{|c|}{$\begin{array}{l}\text { Calibration curve range } \\
(\mathrm{pg} / \mathrm{mL})\end{array}$} & \multicolumn{2}{|c|}{$\begin{array}{l}\text { Labelled standard } \\
\qquad(\mathrm{pg} / \mathrm{mL})\end{array}$} & \multicolumn{2}{|c|}{$\mathbf{R}^{2}(\mathbf{R S D}, \%)$} \\
\hline & $\mathbf{A F B}_{1}$ & $\mathbf{A F M}_{1}$ & $\mathrm{U}-\left[{ }^{13} \mathrm{C}_{17}\right]-\mathrm{AFB}_{1}$ & $\mathrm{U}-\left[{ }^{13} \mathrm{C}_{17}\right]-\mathrm{AFM} \mathbf{M}_{1}$ & $\mathbf{A F B}_{1}$ & $\mathbf{A F M}_{1}$ \\
\hline Dilute\&shoot & $5-100$ & $10-200$ & 10 & 20 & $0.9965(0.04)$ & $0.9967(0.20)$ \\
\hline IAC & $2.5-50$ & $5-100$ & 50 & 100 & $0.9973(0.09)$ & $0.9976(0.10)$ \\
\hline
\end{tabular}



dilute\&shoot and IAC clean-up methods

\section{Dilute\&shoot method}

IAC clean-up method

\begin{tabular}{lcccc} 
& AFB $_{\mathbf{1}}$ & AFM $_{\mathbf{1}}$ & AFB $_{\mathbf{1}}$ & AFM $_{\mathbf{1}}$ \\
\hline LOD (pg/mLurine) & 20 & 40 & 0.8 & 1.5 \\
LOQ (pg/mLurine) & 50 & 100 & 2.5 & 5.0 \\
Working range & $50.0-1000.0$ & $100.0-2000.0$ & $2.5-25.0$ & $5.0-50.0$ \\
$(\mathbf{p g} / \mathbf{m L}$ urine) & - & - & 101 & 98 \\
$\mathbf{R}_{\mathbf{A}}(\%)$ & - & - & 97 & 92 \\
$\mathbf{R}_{\mathbf{E}}(\%)$ & 82 & 111 & 104 & 107 \\
SSE (\%) & 8 & 11 & 6 & 12 \\
RSD $(\%)$ & & & \\
\hline
\end{tabular}


622

1

3

4

5

6

7

8

9

16024

16125

16226

16327

14

11528

16

1629

18

16030

20

26131

22

2632

24

2553

26

2634

28

2635

30

36 36

32

337

34

3538

36

3739

38

3940

40

461

42

4342

44

4543
46

4744

48

4945
585

5146

5347

55

57

5849

59

6650

61

62

63

64

65

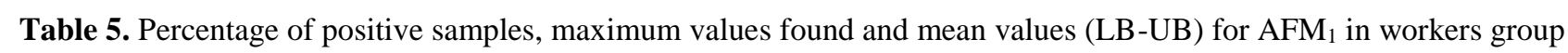
samples

\begin{tabular}{lccc}
\hline & Positive $^{\mathrm{a}}(\%)$ & $\mathrm{Max}^{\mathrm{b}}\left(\mathrm{pg} / \mathrm{mL}_{\text {urine }}\right)$ & ${\text { Mean }(\mathrm{LB}-\mathrm{UB})\left(\mathrm{pg} / \mathrm{mL}_{\mathrm{urine}}\right)}$ \\
\hline Monday and Friday; subjects $(\mathbf{n = 6 3})$ & 13 & 10.5 & $0.5-4.9$ \\
Monday; subjects $(\mathbf{n = 3 2})$ & 13 & $4.6^{\mathrm{c}}$ & $0.4-4.48$ \\
Friday; subjects $(\mathbf{n}=\mathbf{3 1})$ & 13 & 10.5 & $0.6-5.0$
\end{tabular}

aPositive: values above LOD

${ }^{b}$ Max: maximum value

${ }^{\mathrm{c}}$ value below the LOQ 
651 $\frac{1}{652}$

3

4

5

6

7

8

9

1653

16154

1655

1656

1657

15

1658

17

1659

19

2860

21

2861

23

2662

25

2663

27

28

29

30

31

32

33

34

35

36

37

38

39

40

41

42

43

44

45

46

47

48

49

50

51

52

53

54

55

56

57

58

59

60

61

62

63

64

65

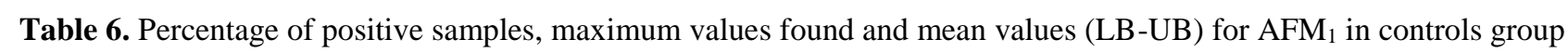
samples

\begin{tabular}{lccc}
\hline & Positive $^{\mathrm{a}}(\%)$ & $\mathrm{Max}^{\mathrm{b}}\left(\mathrm{pg} / \mathrm{mL}_{\text {urine }}\right)$ & ${\text { Mean }(\mathrm{LB}-\mathrm{UB})\left(\mathrm{pg} / \mathrm{mL}_{\mathrm{urine}}\right)}$ \\
\hline Monday and Friday; subjects $(\mathbf{n = 5 7})$ & 11 & 4.1 & $0.3-4.8$ \\
Monday; subjects $(\mathbf{n = 2 9})$ & 7 & $2.8^{\mathrm{c}}$ & $0.2-4.8$ \\
Friday; subjects $(\mathbf{n = 2 8})$ & 14 & $4.1^{\mathrm{c}}$ & $0.4-4.7$ \\
\hline
\end{tabular}

aPositive: values above LOD

bax: maximum value

${ }^{\mathrm{c}}$ value below the LOQ 


\title{
8 Optimization and validation of a LC-HRMS method for aflatoxins
}

\section{determination in urine samples}

Francesca Debegnach ${ }^{1}$, Carlo Brera ${ }^{1}$, Gianmarco Mazzilli ${ }^{1}$, Elisa Sonego ${ }^{1}$, Francesca Buiarelli ${ }^{2}$, Fulvio Ferri ${ }^{3}$, Paolo Giorgi Rossi ${ }^{4}$, Giorgia Collini ${ }^{4}$, Barbara De Santis $^{1 *}$

1. Reparto di Sicurezza Chimica degli Alimenti - Istituto Superiore di Sanità, Viale Regina Elena, 299 - 00161 Rome, Italy

2. Dipartimento di Chimica - "Sapienza" Università di Roma, Piazzale Aldo Moro, 5 - 00185 Rome, Italy

3. Servizio Prevenzione Sicurezza Ambienti di Lavoro, SPSAL - AUSL, Via Giovanni Amendola, 2 - 42122 Reggio Emilia, Italy

4. Servizio Epidemiologia, AUSL - IRCCS, Via Giovanni Amendola, 2 - 42122 Reggio Emilia, Italy

5. *Correspondence author: barbara.desantis@iss.it; Tel: +3906 49902367

\section{Abstract}

Mycotoxins exposure by inhalation and/or dermal contact can occur in different branches of industry especially where heavily dusty settings are present and the handling of dusty commodities is performed. This study aims to explore the possible contribution of the occupational exposure to aflatoxins by analysing urine samples for the presence of aflatoxins $B_{1}$ and $M_{1}$ and aflatoxin $B_{1}-N^{7}$-Guanine adduct. The study was conducted in 2017 on two groups of volunteers, the workers group, composed by personnel employed in an Italian feed plant ( $\mathrm{n}=32)$, and a control group $(n=29)$, composed by the administrative employees of the same feed plant; a total of 120 urine samples were collected and analysed. A screening method and a quantitative method with high resolution mass spectrometry determination were developed and fully validated. Limit of detections were 0.8 and $1.5 \mathrm{pg} / \mathrm{mL}_{\text {urine }}$ for aflatoxin $\mathrm{B}_{1}$ and $\mathrm{M}_{1}$, respectively. No quantitative determination was possible for the adduct aflatoxin $\mathrm{B}_{1}-\mathrm{N}^{7}$-Guanine. Aflatoxin $\mathrm{B}_{1}$ and its adduct were not detected in the analysed samples, aflatoxin $\mathrm{M}_{1}$, instead, was found in 14 samples (12\%) within the range $1.9-10.5 \mathrm{pg} / \mathrm{mL}_{\text {urine. }}$ Only one sample showed a value above the limit of quantification $\left(10.5 \mathrm{pg} / \mathrm{mL}_{\text {urine }}\right)$. The absence of a statistical difference between the mean values for workers and the control group were compared suggests
\end{abstract}


$\mathrm{M}_{1}$ in the collected urine samples, also the contribution from the diet to the overall exposure is to be considered negligible.

\section{Keywords}

Biomonitoring, Biomarker, Mycotoxin, Aflatoxin, Metabolites, LC-Orbitrap, LC-HRMS

\section{Introduction}

Among xenobiotics, mycotoxins, secondary metabolites of fungal origin, are the most harmful hazards with high toxic potency and recognized adverse impacts on human and animal health. More than 500 mycotoxins are known, but scientific studies focus on those that exert carcinogenic and/or toxic activity, and only few of them are regulated worldwide (Stein et al. 2017; CAST 2003; FAO 2004). Among mycotoxins, aflatoxins (AFs) represent one of the most concerning class of chemical compounds with a focus of interest on aflatoxin $\mathrm{B}_{1}\left(\mathrm{AFB}_{1}\right)$ that, due to its acute and chronic toxic effects, have raised the interest of the scientific community. The primary target organ affected by aflatoxin $\mathrm{B}_{1}$ exposure is the liver, and several epidemiological studies related $\mathrm{AFB}_{1}$ exposure to cellular hepatocarcinoma, report it as one of the major cause of cancer-related deaths in different parts of the world (Wild et aland Turner- 2002). AFB 1 is a genotoxic and carcinogenic substance, classified under group 1 by the International Agency for Research on Cancer (IARC 1993). AFs can occur in crops at pre-harvest, harvest and post-harvest stages as a result of different co-occurring environmental conditions and poor management practices (handling and storage). The expected global warming of +2 ${ }^{\circ} \mathrm{C}$ is likely to cause a sensible climate change leading to conducive environmental conditions for AFs production in Northern-Europe, where currently no occurrence is significantly present (Battilani et al. 2016). Therefore, validating new methods for AFs determination becomes particularly relevant to be applied in newly exposed geographical regions. The most common route of exposure to mycotoxins is the ingestion through the diet due to the consumption of directly or indirectly contaminated food. Furthermore, humans and animals can also be exposed to mycotoxins through inhalation and/or dermal contact with contaminated dusts (Brera et al. 2002; Doi and Uetsukaet al. 2014; Viegas et al. 2014 $;$; Viegas et al. 2017). Several studies reported a higher prevalence of lung carcinogenesis and bronchus and trachea tumours in workers exposed to aflatoxins contaminated dusts (McLaughlin et al. 1987; Olsen et al. 1988; Ghosh et al. 1997; Saad-Hussein et al. 2013,; Sad-Hussein al. 2014), especially in branches of industry where the storage, loading, milling and handling of dusty commodities (such as grains, feed, spices, coffee, etc.) is performed. Due to their 
severe toxicological implications, exposure to aflatoxins must be characterized by an accurate evaluation. Commonly, two different approaches can be followed for targeting this issue: via dietary exposure assessment and/or via biomonitoring studies. The overall metabolic pathway of $\mathrm{AFB}_{1}$ is quite complex and corresponds to the formation of a number of metabolites that could be associated not only to the dose of the parent mycotoxin, but also to the biological response to the exposure -and to the degree of individual sensitivity to adsorption and metabolism of the toxic agent (Groopman 1994). Validated exposure biomarkers for $\mathrm{AFB}_{1}$ (urinary aflatoxin $\mathrm{M}_{1}, \mathrm{AFB}_{1}-\mathrm{N}^{7}$-Guanine) were established almost 20 years ago (Groopman et al. 1993), they were critical in confirming aflatoxins as potent liver carcinogens, and more importantly, they are being used to assess the effectiveness of intervention strategies (Cramer et al.and Uetsuka 2017; Turner et al. 2012).

Biomonitoring studies have been increased over the last 8 years. In a recent publication Viegas (Viegas et al. 2018) reviewed the use of biomonitoring in assessing occupational exposure to mycotoxin in different settings and $58 \%$ of the reviewed works assessed aflatoxins exposure. Despite the impossibility to distinguish between dietary and air-dust contamination, the literature review clearly showed that, under certain circumstances, workers were significantly more exposed than the control group (Malik et al. 2014; Saad-Hussein et al. 2014; Viegas et al. 2016). In Italy a first study on occupational exposure to aflatoxins was conducted in 2014 in two feed companies, to assess if workers occupied in dusty indoor settings were differently exposed than workers occupied in administrative units (control group) (Ferri et $\left.\mathrm{al}_{\_,}, 2017\right)$. To monitor the situation and to assess the effect of new agricultural season, the same scheme of the study was replicated in 2017 within a different analytical framework, where also the guanine metabolite was included. The present study aims to explore the role of the occupational exposure to aflatoxins by analysing urine samples to assess the presence of aflatoxins $\mathrm{B}_{1}$ and $\mathrm{M}_{1}$ and aflatoxin $\mathrm{B}_{1}-\mathrm{N}^{7}$-Guanine adduct in a group of workers, operating in risky workplaces, and a control group. The group of volunteer workers, operating in a setting of the feed sector, potentially exposed to mycotoxins through the inhalation of contaminated dust and/or by dermal contact and a control group, composed by administrative employees working on the same feed plant, were enrolled in the study. Aflatoxins determination was performed by a high-resolution mass spectrometry (LC-HRMS) technique. For sample preparation, a dilute\&shoot method and a quantitative method based on immunoaffinity column purification step were developed and fully validated. Moreover, due to the unavailability of commercial standard of $\mathrm{AFB}_{1}-\mathrm{N}^{7}-\mathrm{Guanine}$, the adduct was synthetized and used for the method set up and for qualitative analysis (presence/absence) in the collected samples.

\section{Materials and Methods}

Chemicals and reagents 
Chemicals and solvents used for sample preparation were LC-MS grade. Methanol, formic acid and LC-MS grade water were purchased from Fisher Scientific (Milano, Italy), $\mathrm{AFB}_{1}$ from Aspergillus flavus (purity $\geq 98 \%$ ) was from Sigma-Aldrich (Darmstadt, Germany). The analytical reference standard of $\mathrm{AFM}_{1}$ was purchased as stock solution (0.5 $\mu \mathrm{g} / \mathrm{mL}$ in acetonitrile) from Biopure ${ }^{\circledR}$ (Tulln, Austria). The isotopically labelled internal standards $\mathrm{U}-\left[{ }^{13} \mathrm{C}_{17}\right]-\mathrm{AFB}_{1}$ $\left(99.3 \%{ }^{13} \mathrm{C}\right)$ and $\mathrm{U}-\left[{ }^{13} \mathrm{C}_{17}\right]-\mathrm{AFM}_{1}\left(98.3 \%{ }^{13} \mathrm{C}\right)$ were also purchased as acetonitrile solution $(0.5 \mu \mathrm{g} / \mathrm{mL})$ from Biopure ${ }^{\circledR}$ (Tulln, Austria). The concentration reported in the certificate accompanying the reference standard purchased as solution was considered for quantification purpose. The $\mathrm{AFB}_{1}$ powder was reconstituted with $100 \% \mathrm{ACN}$ and the concentration was assessed by molar absorbance value following the procedure reported in the official Methods of Analysis of AOAC (AOAC 2005). The $\mathrm{AFB}_{1}-\mathrm{N}^{7}$-Guanine adduct was not commercially available at the moment of the study and was synthetized as reported below.

\section{$A F B_{1}-N^{7}$-Guanine adduct synthesis and identification}

The synthesis was conducted accordingly with Vidyasagar et al. (1997) as follows: meta-chloroperoxybenzoic acid (MCPBA), $20 \mathrm{mg}$ in $4 \mathrm{~mL}$ of dichloromethane, was washed with $100 \mathrm{mM} \mathrm{mmol} / \mathrm{L}$ phosphate buffer, $\mathrm{pH} 7.4$ (4 mL x 4). The resulting MCPBA solution was passed through anhydrous sodium sulphate to remove residual water. $\mathrm{AFB}_{1}(0.64$ $\mu$ moles) was dissolved in $250 \mu \mathrm{L}$ of dichloromethane and was converted to $\mathrm{AFB}_{1}-8,9$-epoxide by addition of $250 \mu \mathrm{L}$ of the above MCPBA solution ( $4 \mu$ moles) and $500 \mu \mathrm{L}$ of $100 \mathrm{mM}$ mmol/L phosphate buffer, $\mathrm{pH} 7.2$. The reaction was carried out at 5 - $\mathrm{C}$ for $100 \mathrm{~min}$ with continuous vigorous stirring. At the end of $100 \mathrm{~min}$ the buffer fraction was pipetted out. $0.32 \mu$ moles of Guanine, previously dissolved in 0.1 mol/LN $\mathrm{HCl}_{2}(0.32 \mu$ moles $)$ waswere added to taken in 500 $\mu \mathrm{L}$ of $100 \mathrm{mM}$ mmol/L phosphate buffer, $\mathrm{pH} 7.4$ (maximum solubility of guanine in phosphate buffer was found to be $140 \mu \mathrm{g} / \mathrm{mL}$ ). The buffer with guanine was added to the tube containing $\mathrm{AFB}_{1}-8$,9-epoxide in dichloromethane and the reaction was continued for $60 \mathrm{~min}$ at $5{ }^{\circ} \mathrm{C}$ with continuous vigorous stirring. At the end of $60 \mathrm{~min}$ the reaction mixture was centrifuged at $4000 \mathrm{rpm}$ for $5 \mathrm{~min}$. The organic phase was separated and the buffer fraction was repeatedly washed with dichloromethane ( $500 \mu \mathrm{L} \times 3$ times). The adduct identification was based on the observation of the molecular ion and at least one fragment specific for the analyte after injection in the LC-HRMS system, according to the guidance document on identification of mycotoxins in food and feed (European-ECCommission 2016). Due to the difficulties in assessing the concentration level of the synthetized adduct, the diluted buffer fraction was used for testing the IAC cross reactivity during method development and for a qualitative evaluation of presence/absence in the collected urine samples.

\section{Study design}


The investigation was conducted in the same feedstuff plant involved in the first study previously published by Ferri et

The study was conducted under the supervision of the Local Health Unit of Reggio Emilia and was approved by the Ethical Committee of the Reggio Emilia province. All urine donors were informed about the purpose of the study and a formal consent was individually signed prior to inclusion in the study.

\section{Sample preparation}

Dilute\&shoot sample preparation

Before analysis, all urine samples were equilibrated to room temperature and homogenized by shaking thoroughly.

Aliquots of $100 \mu \mathrm{L}$ urine were mixed with $860 \mu \mathrm{L}$ of $\mathrm{H}_{2} \mathrm{O}$ LC-MS grade; for quantification purpose $20 \mu \mathrm{L}$ of $\mathrm{U}-\left[{ }^{13} \mathrm{C}_{17}\right]-$ $\mathrm{AFB}_{1} 5 \mathrm{ng} / \mathrm{mL}$ in acetonitrile and $20 \mu \mathrm{L}$ of $\mathrm{U}-\left[{ }^{13} \mathrm{C}_{17}\right]-\mathrm{AFM}_{1} 10 \mathrm{ng} / \mathrm{mL}$ in acetonitrile were added to the sample. The diluted sample was centrifuged for 10 minutes at $3500 \mathrm{xg}$ (RCF) before the injection of $10 \mu \mathrm{L}$ into the UHPLC-HRMS system.

Immunoaffinity clean-up

Before analysis, all urine samples were equilibrated to room temperature and homogenized by shaking thoroughly. Aliquots of $2 \mathrm{~mL}$ urine were mixed with $10 \mathrm{~mL}$ of phosphate buffered solution (PBS, $\mathrm{pH}=7.4$ ) and passed through the 
immunoaffinity column (IAC) for purification (Easy-extract ${ }^{\circledR}$ aflatoxins, from R-Biopharm, Darmstadt, Germany). The IAC was washed with $30 \mathrm{~mL}$ of $\mathrm{H}_{2} \mathrm{O}(10+10+10 \mathrm{~m}+\underline{\mathrm{L}})$, then the toxins were eluted with $1 \mathrm{~mL}$ of $\mathrm{MeOH}(500+500 \mu \mathrm{L})$. Finally, $500 \mu \mathrm{L}$ of eluted sample were added with $20 \mu \mathrm{L} \mathrm{U}-\left[{ }^{13} \mathrm{C}_{17}\right]-\mathrm{AFB}_{1} 2.5 \mathrm{ng} / \mathrm{mL}$ in ACN, $20 \mu \mathrm{L} \mathrm{U}-\left[{ }^{13} \mathrm{C}_{17}\right]-\mathrm{AFM}_{1} 5$ $\mathrm{ng} / \mathrm{mL}$ in ACN and $460 \mu \mathrm{L}$ of $\mathrm{H}_{2} \mathrm{O}$. A volume of $20 \mu \mathrm{L}$ was injected into the UHPLC-HRMS system.

\section{LC-HRMS Analysis}

Determination was performed by UHPLC-HRMS analysis. Chromatographic separation was performed using UHPLC Dionex UltiMate $3000^{\circledR}$ (Thermo Scientific, San Jose, CA, USA). An Acquity UPLC ${ }^{\circledR}$ BEH C18 column $(1.7 \mu \mathrm{m}, 100$ $\times 2.1 \mathrm{~mm}$, from Waters, Milford, MA, USA) was used at a temperature of $40_{-}^{\circ} \mathrm{C}$. The flow rate was $0.3 \mathrm{~m}+\underline{\mathrm{L}} / \mathrm{min}$, mobile phases A and B were respectively water and methanol containing $0.002 \%$ formic acid (v/v) and $2 \mathrm{mM} \underline{\mathrm{mmol} / \mathrm{L}}$ ammonium formate. The following gradient was applied: $20 \%$ B increase to $99 \%$ in 10 min, keep isocratic at $99 \%$ B for $4 \mathrm{~min}$, from 14 to $14.6 \mathrm{~min}$ return to $20 \% \mathrm{~B}$, and finally re-equilibrate the column at $20 \% \mathrm{~B}$ for $2.4 \mathrm{~min}$. High-resolution MS analysis was performed using Q Exactive ${ }^{\mathrm{TM}}$ Quadrupole-Orbitrap ${ }^{\mathrm{TM}}$ equipped with Heated ElectroSpray Ionization (HESI) source (Thermo Scientific, San Jose, CA, USA). The following ESI (+) parameters were used: source voltage $3.5 \mathrm{kV}$, in-source CID $18 \mathrm{eV}$, capillary temperature $320_{-}^{\circ} \mathrm{C}$, auxiliary gas heater temperature $350_{-}^{\circ} \mathrm{C}$, sheath gas flow 40, S-lens RF level 75 and auxiliary gas flow 14. The MS acquisition was performed in Full Scan/Data Dependent (full MS/dd-MS ${ }^{2}$ ) for confirmatory purpose. Precursor ion, fragments and collision energy used for the determination of the selected mycotoxins are reported in Table 2. All analytical batches included analysis of appropriate extraction and solvent blanks, solvent calibration curves at the beginning and end of the analytical batch, and injection of a calibration level every 10 sample injections to ensure LC-MS stability throughout the run. For data acquisition and processing, Xcalibur $^{\mathrm{TM}}$ software 4.0.27.19 was used.

\section{Analytical quantification}

For mycotoxins quantification an internal standard (ISTD) approach was adopted. The internal standard for AFB $_{1}$ and $\mathrm{AFM}_{1}$ was the ${ }^{13} \mathrm{C}$ isotope labelled molecule in which all carbon atoms are substituted by the stable isotope ${ }^{13} \mathrm{C}$. Six points calibration curve was obtained by plotting the response ratio (standard area/ ${ }^{13} \mathrm{C}$ area) versus the concentration

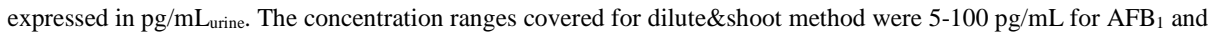
$10-200 \mathrm{pg} / \mathrm{mL}$ for $\mathrm{AFM}_{1}$, corresponding to $50-1000 \mathrm{pg} / \mathrm{mL}_{\text {urine }}$ and $100-2000 \mathrm{pg} / \mathrm{mL}_{\text {urine }}$ for $\mathrm{AFB}_{1}$ and $\mathrm{AFM}_{1}$, respectively. For IAC method the ranges were $5-50 \mathrm{pg} / \mathrm{mL}$ for $\mathrm{AFB}_{1}$ and $10-100 \mathrm{pg} / \mathrm{mL}$ for $\mathrm{AFM}_{1}$, corresponding to 2.5-25 pg/mL $\mathrm{mrine}_{\text {and }} 5-50 \mathrm{pg} / \mathrm{mL}_{\text {urine }}$ for $\mathrm{AFB}_{1}$ and $\mathrm{AFM}_{1}$, respectively. The calibration curve was obtained by fitting the data with a linear regression model based on least squares method. 


\section{Validation criteria}

Identification criteria were set for all the analysed mycotoxins. Linearity and limit of detection (LOD) and

quantification (LOQ) of the analytical methods were assessed. Precision and trueness were assessed from repeated analyses on spiked blank urine samples. Precision was evaluated by calculating the intermediate relative standard deviation (repeated analyses on different days), while trueness was estimated in terms of apparent recovery $\left(\mathrm{R}_{\mathrm{A}}\right)$ Extraction efficiency $\left(\mathrm{R}_{\mathrm{E}}\right)$ and matrix effect $(\mathrm{SSE})$ were also evaluated for validation purpose.

\section{Method validation}

For both methods, linearity of the method was evaluated from six points calibration curves injected in triplicate for three consecutive days. Regression lines were plotted applying a linear regression model based on least squares method. The linearity was assessed by visual checking of the residual plot of response ratios (plotted in y-direction) versus the respective concentration levels (plotted in $\mathrm{x}$-direction). The final estimated linearity model was verified using the lackof-fit test (significance of the test with $\mathrm{p}_{\text {value }}$ below 0.05 ), to confirm that the selected regression and linearity were acceptable. Once visual checking of the residual and lack-of-fit test passed, the R squared coefficient was taken as a measure of linearity.

According to the criteria reported in the SANTE/12089/2016 guidance document_on identification of mycotoxins in food and feed (European-Cemmission 2016), the retention time (RT) of the analyte in the sample extract should correspond to that of the average of the calibration standards measured in the same sequence with a tolerance of $\pm_{-} 0.1$ min. Moreover, for the ISTD added to the sample extract, the RT of the analyte should correspond to that of its labelled ISTD with a tolerance of $\pm 0.05 \mathrm{~min}$. For HRMS analysis identification is based on observation of the molecular ion (or if not available, adducts) and one fragment that is specific for the selected analyte. According to Wenzl et al. (2016), spiked blanks approach was used for LOD and LOQ assessment, by analysing the spiked sample in ten replicates under repeatability conditions. The variability expressed as standard deviation obtained for the ten analyses of spiked blanks was used for the estimation of the critical value of LOD. Calculations were carried out according to Equation 1 and 2. 
The LOQ values obtained with the theoretical calculation approaches were included in the validation as the lowest concentration level.

10

For dilute\&shoot method, the matrix effect was examined according to Sulyok et al. (2006) assessing the matrix

induced enhancement or suppression during analysis. For this purpose, calibration curves in solvent (5 calibration points in the range of $40-200 \mathrm{pg} / \mathrm{mL}$ for $\mathrm{AFB}_{1}$ and $80-400 \mathrm{pg} / \mathrm{mL}$ for $\mathrm{AFM}_{1}$, constructed by plotting signal intensity versus the analyte concentration) were compared with matrix-matched calibration curves (blank sample 1:10 diluted spiked at 5 levels, curves obtained by plotting the signal intensity against the actual spiking level). The slopes of the resulting calibration curves were used for signal suppression/enhancement (SSE) calculation (Equation 3).

$\operatorname{SSE}(\%)=100 * \frac{\text { slope }(\text { matrix }- \text { matched standard })}{\text { slope }(\text { solvent standard })}$

\section{For IAC method, apparent recovery, matrix effect and extraction recovery were assessed on 5 different levels of} contamination, including the calculated LOQ values, for each level triplicate analyses of spiked blank sample on 2 consecutive days were performed. The obtained data were used for apparent recovery $\left(\mathrm{R}_{\mathrm{A}}\right)$, matrix effect and extraction recovery $\left(\mathrm{R}_{\mathrm{E}}\right)$ calculations and for precision assessment. The $\mathrm{R}_{\mathrm{A}}$ is calculated as the ratio between the slope of the spiked sample curve, obtained from the spiked samples, and the slope of the calibration curve in pure solvent (Equation 4). In this case, the curves were obtained considering the area and not the ratio with the labelled internal standard added for each mycotoxin. The $\mathrm{R}_{\mathrm{A}}$ represents the influence of the whole analytical process (sample preparation + determination) on the signal and it is also referred to as overall or total recovery of a method. $\mathrm{R}_{\mathrm{A}}$ was the parameter used for trueness evaluation.

$\mathrm{R}_{\mathrm{A}}(\%)=100 * \frac{\text { slope (spiked sample) }}{\text { slope }(\text { solvent standard) }}$

The matrix effect was evaluated in terms of Signal Suppression/Enhancement (SSE) and it was calculated, according to Equation 5, as the ratio between the mean area of the labelled ISTD in the spiked sample extract and in the pure solvent standard solution.

$\operatorname{SSE}(\%)=100 \times \frac{\text { area } U-\left[13 C_{17}\right]-A F B_{1} \text { sample }}{\text { area } U-\left[13 C_{17}\right]-A F B_{1} \text { standard }}$ 
The $\mathrm{R}_{\mathrm{E}}$, accounting to incomplete extraction of the analyte from the matrix, was calculated from $\mathrm{R}_{\mathrm{A}}$ and SSE, according to Equation 6.

$\mathrm{R}_{\mathrm{E}}(\%)=100 * \frac{\mathrm{R}_{\mathrm{A}}}{\mathrm{SSE}}$

The effect of random errors on the measurements were assessed and quantified as the relative standard deviation (RSD) of repeated independent analyses conducted in intermediate conditions of repeatability within the laboratory $\left(\mathrm{RSD}_{\mathrm{LR}}\right)$. Instrumental laboratory reproducibility of the LC-HRMS system was also evaluated by injecting on three consecutive days (inter-run) and in replicates (intra-run) a neat solvent standard solution ( $\mathrm{AFB}_{1} 150 \mathrm{pg} / \mathrm{mL}$ and $\mathrm{AFM}_{1} 300 \mathrm{pg} / \mathrm{mL}$ ). Moreover, the intermediate precision of the whole method was evaluated by analyzing daily independent urine sample spiked at the same contamination level as an internal control sample (inter-day). The performance criteria for precision, quantified with standard deviation of repeatability within the laboratory $\left(\mathrm{s}_{\mathrm{LR}}\right)$ and expressed in percentage as $\mathrm{RSD}_{\mathrm{LR}}$, was set at $15 \%$ of variability, including any source of instrumental and analytical possible random errors. Precision was estimated in terms of intermediate precision $\mathrm{RSD}_{\mathrm{LR}}$ of repeatability.

\section{Results and Discussion}

\section{Sample preparation and LC-HRMS analysis}

During method set up two urine:water dilution factors, namely 1:5 and 1:10, were tested for dilute\&shoot approach. The 1:10 dilution gave better results in terms of SSE and was selected for the analysis. The IAC purification step was introduced in order to reduce the LOD/LOQ values. The employed IAC contains specific antibodies to aflatoxins $\mathrm{B}_{1}$, $B_{2}, G_{1}, G_{2}$ and $M_{1}$, no specific information werewas given by the supplier for $A_{F B}-N^{7}$-Guanine. To evaluate the risk of adduct loss during purification, the synthetized adduct was applied to the IAC, eluted according to method protocol and the presence of the adduct was confirmed by LC-HRMS identification.

HRMS conditions were set by direct infusion of standard solution for $\mathrm{AFB}_{1}$ and $\mathrm{AFM}_{1}$, while for $\mathrm{AFB}_{1}-\mathrm{N}^{7}-\mathrm{Guanine}$ the selection of collision energy and specific fragments were guided by the work of Walton et al. (2001). AFB 1 produces sodiated adduct in a non negligible amount when compared with protonated adduct during electrospray ionization step, although $\mathrm{AFB}_{1}$ is unlikely produce ammonium adduct, the presence of the ammonium in the mobile phase suppresses the sodiated adduct in favour of the protonated one. This is the reason for the presence in the mobile phases of formic acid and ammonium formate. For quantitative purpose the protonated adducts were selected, for $\mathrm{AFM}_{1}$, since it was not 
possible to reduce the sodiated adduct production by varying source parameters, the sum of the protonated and sodiated adduct was considered.

\section{Validation parameters}

Linearity was checked in the working range by the lack-of-fit test based on the analysis of variance (F test with $\mathrm{p}$ value $<0.05)$ and the plot of the residual values randomly distributed around zero, confirming the linearity. During routine analytical sessions an $\mathrm{R}^{2}>0.990$ was set as a criterion for calibration curve acceptability. In Table 3 the calibration curve ranges, the amount of ISTD added to each calibration level and the correlation coefficients $\left(\mathrm{R}^{2}\right)$ obtained for each mycotoxin/matrix combination are reported.

The performance characteristics, in terms of $\mathrm{R}_{\mathrm{A}}, \mathrm{SSE}$ and $\mathrm{R}_{\mathrm{E}}$, are summarized in Table 4 together with LOD and LOQ values and the working range of the two analytical procedures. Both methods may be applied for quantitative analysis of $\mathrm{AFB}_{1}$ and $\mathrm{AFM}_{1}$ as well as for the evaluation of presence/absence of the $\mathrm{AFB}_{1}-\mathrm{N}^{7}$-Guanine adduct. The dilute\&shoot method is characterized by higher LOD and LOQ values when compared with the IAC clean-up method, but on the other hand the dilute\&shoot approach is very quick and characterized by a conservative approach with respect to the sample, giving the possibility of a retrospective analysis on the acquired data. Due to the absence of a sample pretreatment only matrix effect, in terms of SSE, and precision, in terms of $\mathrm{RSD}_{\mathrm{LR}}$, were evaluated during dilute\&shoot method validation. SSE percentages are very close to $100 \%$ due to the dilution applied to the urine sample; method precision was assessed by performing 8 independent analyses at the LOQ level. The IAC clean-up method was fully validated, trueness was evaluated in terms of apparent recovery $\left(\mathrm{R}_{\mathrm{A}}\right)$ while precision was assessed by laboratory reproducibility $\mathrm{RSD}_{\mathrm{LR}}$ measures. Although the IAC clean-up, which is a very selective approach, was used, the influence of the matrix was also evaluated, and the percentages of SSE for $\mathrm{AFB}_{1}$ and $\mathrm{AFM}_{1}$ found confirmed that the influence of the matrix on the instrumental response is very limited.

LOD and LOQ of analytical methods always represent a challenge being the bottleneck for the reliability of the analytical results and also for the further processing of the findings (i.e. data mining). Modern HRMS instruments makes it possible to reach high sensitivities with low detection limits, and especially when methods are targeted, good benchmarks can be achieved. Among the most recent studies on the biomonitoring of aflatoxins, the lowest values for $\mathrm{AFM}_{1}$ were found in the range of $0.13-0.6 \mathrm{pg} / \mathrm{mL}_{\text {urine }}$ and in the $0.4-1.8 \mathrm{pg} / \mathrm{mL}$ urine for LOD and LOQ, respectively (Giolo et al. 2012; Romero et al. 2010). Although these values represent a gold standard benchmark, they are not covered by the strict performance requirements of accuracy, which instead were met at $10 \mathrm{pg} / \mathrm{mL}$ urine (Giolo et al. 2012) and $4 \mathrm{pg} / \mathrm{mL}_{\text {urine }}$ (Romero et al. 2010). Thus, the LOD/LOQ values obtained in the IAC method, validated under strict performances, are in alignment with the findings in other bomonitoring works for $\mathrm{AFM}_{1}$. Notwithstanding, all the 
positive samples were in the range of values between LOD and LOQ, revealing the crucial need to stress the method to reach lower levels. In conclusion, the general validation results obtained in this study are considered satisfactory either for screening and for confirmation and the method is considered to suit for the production accurate data for biomonitoring purposes.

\section{Analytical results}

Statistical analysis and Data handling - Left censored data

The hypothesis of normal distribution (Shapiro-Wilk test) was refused, thus non-parametrical tests were used for the statistical treatment of the analytical results. All possible differences between concentration levels of mycotoxins in exposed and non-exposed groups were explored by a Wilcoxon rank-sum test. To assess the correlation between mycotoxin levels, a Spearman's rank correlation coefficient (or Spearman's rho) was used. All tests were conducted with a level of significance of 5\%. Analyses were conducted by means of STATA14 software (Stata/IC 14.0, Copyright 1985-2015 StataCorp LP). Under the rigid identification criteria for analyte determination, namely the RT criteria $(\mathrm{RT} \pm 0.1 \mathrm{~min}$ with respect to the standard $\mathrm{RT})$ and the presence of the precursor ion and at least one characteristic fragment for each considered analyte, it was decided to include and report also all the values below LOQ obtained by the interpolation of the calibration curve. Thus, values lower than LOQ were reported in the dataset as positive samples provided that the identification criteria were met. The results evaluation included also the reporting of the lower and upper bound (LB and UB) mean values (EFSA 2010). These values were calculated applying a substitution method for which in the LB calculations the results lower than LOQ were substituted with zero, while in the UB the results lower than LOQ were substituted with LOQ value depending on the method.

\section{Analysis of samples}

The collected urine samples were analysed first with the dilute\&shoot method, through which none of the sample showed a measurable level of $\mathrm{AFB}_{1}$ or $\mathrm{AFM}_{1}$, including $\mathrm{AFB}_{1}-\mathrm{N}^{7}-$ Guanine which was not detected. To overcome the limitations coming from the detection limit threshold of the dilute\&shoot method and verify that the negativity of the results could be caused by the level of LOD/LOQ declared, it was decided to set up and validate a method with lower LOQ. A purification step was introduced using an IAC clean-up to clean and concentrate the urine sample. By using this method for reprocessing the urine samples, $\mathrm{AFB}_{1}$ and its adduct were not detected, $\mathrm{AFM}_{1}$, instead, was found in 14 samples (12\%) within the range 1.9-10.5 pg/mLurine. Only one sample, coming from the workers' group, showed a value above the LOQ $\left(10.5 \mathrm{pg} / \mathrm{mL}_{\text {urine }}\right)$ and it is a sample from the workers group. Tables 5 and 6 summarize the percentages of positive samples, maximum values found, and mean values (LB-UB) for worker and control groups, respectively. It 
should be noted that when values reported for $\mathrm{AFM}_{1}$ are below the LOQ they were considered as affected by a standard uncertainty higher than $25 \%$, which was the performance criteria set for maximum standard uncertainty for the LOQ. The LB-UB values reflect the optimistic and pessimistic scenario range of possible mean values.

Figure 1 shows the data trend for $\mathrm{AFM}_{1}$ in urine for both groups, Monday and Friday sampling. On the left side LB substitution method was applied, due to the high number of non-detected (87\%), box plot is flattened to zero. On the right side the box plot reports all the positive values are reported. The band inside the box is the second quartile (P50, median). Dots indicates suspected outliers. Whiskers are set from minimum to maximum value. First and third quartiles (P25 and P75) can be found at the bottom and the top of the box, respectively.

No statistical difference for $\mathrm{AFM}_{1}$ was observed between Monday and Friday samples in each group (exposed and nonexposed workers). To note that among the positive results two individuals of the exposed workers group showed AFM in both Monday and Friday deliveries $\left(3.3\right.$ and $3.0 \mathrm{pg} / \mathrm{m} \underline{L}_{\text {urine }}$ and 4.6 and $10.5 \mathrm{pg} / \mathrm{mL} \underline{1}_{\text {urine, Monday and Friday values }}$ for each individual, respectively. Further statistical analyses were performed merging data of Monday and Friday data (63 analyses for exposed workers group and 57 for non-exposed workers group). Eight samples (13\%) resulted positive in the workers' group where the highest contaminated sample was found (10.5 pg/m $\left.\underline{\mathrm{L}}_{\text {urine }}\right)$; six samples $(11 \%)$ were positive in the control group, the higher detected value was $4.1 \mathrm{pg} / \mathrm{m}+\underline{L}$ urine. In order to find differences among the positive values found in workers and control group, a Wilcoxon rank-sum test was performed but no statistical significances were highlighted; even exploring the two days of urine delivery, no differences were highlighted. The absence of $\mathrm{AFB}_{1}$ and its adduct, together with the absence of a statistical difference when the mean values of $\mathrm{AFM}_{1}$ for workers and control groups were compared, suggests that in this specific setting, no professional exposure occurs. Moreover, considering the very low level of $\mathrm{AFM}_{1}$ in the collected urine samples, also the contribution from the diet to the overall exposure is to be considered negligible.

\section{Conclusions}

This study presents a method, performed by a high-resolution mass spectrometry (LC-HRMS) technique, to detect $\mathrm{AFB}_{1}$ and aflatoxin biomarkers, namely $\mathrm{AFM}_{1}$ and aflatoxin-N7-Guanine. If compared with the previous study conducted in 2014 (Ferri et al. 2017), the present work tackles with an improvement of method sensitivity (1.5 $\mathrm{pg} / \mathrm{m}+\underline{L}_{u}$ une versus $25 \mathrm{pg} / \mathrm{mL} \underline{1}_{u r i n e}$ in Ferri et al. (2017). High percentages of workers positive for $\mathrm{AFB}_{1}$ were reported in several studies conducted in EU (Portugal, Italy, Denmark) (Olsen et al. 1988; Viegas et al. 2018; Ferri et al. 2017) emphasizing that occupational exposure might be critical in certain settings, such as feed plants, in which indoor areas can be conducive of highly contaminated dust particles. In this study, morning urine samples were collected during one working week from a cohort of occupational exposed workers of a feed company and from a control group. The presence of only one positive sample of $\mathrm{AFB}_{1}$ and the lack of statistical difference between mean values of $\mathrm{AFM}_{1}$ in 
workers and control groups, suggests that in this specific setting, the primary route of exposure to AFs is more likely to be attributed to the diet and not to the respiratory route when inhalation or dermal contact of aerosolized contaminated dusts occur. However, the attention and focus to AFs can't never be reduced to a no-risk situation, since, due to the direct correlation between aflatoxins occurrence and climate changes, a systematic monitoring of the health status of citizen (including workers) potentially exposed to dusts contaminated by these toxic compounds, has to be duly undertaken.

\section{Compliance with ethical standard}

The study has been approved by the Ethical Committee of Reggio Emilia Province and performed in accordance with the ethical standards laid down in the 1964 Declaration of Helsinki and its later amendments.

Conflict of Interest The authors declare no conflict of interest.

\section{Acknowledgements}

This research was funded by EFSA: GP/EFSA/AFSCO/2017/05PERFORMANCE: International Conference "The Burden of Mycotoxins on animal and human health" and Research Project "Biomonitoring data as a tool for assessing aflatoxin $\mathrm{B}_{1}$ exposure of workers - BIODAF". Sole responsibility lies with the author and the Authority is not responsible for any use that may be made of the information contained therein.

Gabriele Moracci, Paola De Santis, Maria Cristina Barea Toscan and Giuliana Verrone (Istituto Superiore di Sanità), and Massimo Magnani (Servizio Prevenzione Sicurezza Ambienti di Lavoro) are acknowledged for their technical assistance.

\section{References}

AOAC - Association of Official Agricultural Chemists (2005) Official mMethods of Aanalysis of AOAC international (2005), Ch.49.2.02 Method, 970.44

Battilani P, Toscano P, Van der Fels-Klerx HJ, Moretti A, Camardo Leggieri M, Brera C, Rortais A, Goumperis T,

Robinson T (2016) Aflatoxin $B_{1}$ contamination in maize in Europe increases due to climate change. Sci Rep 6:24328. https://doi.org/10.1038/srep24328 
Brera C, Caputi R, Miraglia M, Iavicoli I, Salerno A, Carelli G (2002) Exposure assessment to mycotoxins in workplaces: $\underline{a} A$ flatoxins and ochratoxin A occurrence in airborne dusts and human sera. Microchem J 73(1):167-173. https://doi.org/10.3390/toxins10090342

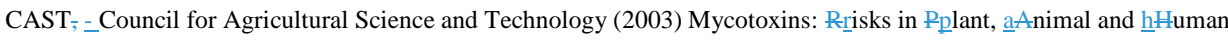
Ssystems. Task fForce rReport ISSN 0194-4088; No- 139. ISBN $1-887383-220$

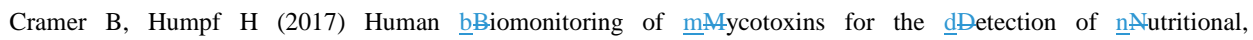
eEnvironmental and ㅇccupational eExposure. In: Viegas C, Viegas S, Gomes A, Täubel M, Sabino R (eEds) Exposure to mMicrobiological aAgents in iIndoor and oØccupational eEnvironments. -SSpringer, Cham, pp 191-212. https://doi.org/10.1007/978-3-319-61688-9_9

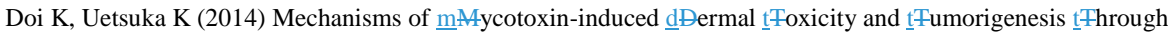
o○xidative $\underline{s} S$ tress-related pPathways. J Toxicol Pathol 27(1):-1-10. https://doi.org/10.1293/tox.2013-0062 EFSA - European Food Safety Authority (2010) Management of left-censored data in dietary exposure assessment of chemical substances. EFSA J 8:1557. Available from: https://doi.org/10.2903/j.efsa.2010.1557 EC-European Commission $[E C]-[E C]-(2016)$ Guidance document on identification of mycotoxins in food and feed. (SANTE/12089/2016). Available from: http://tinyurl.com/y86zckkj

FAO - Food and Agriculture Organization of the United Nations (2004) Worldwide regulations for mycotoxins in food and feed in 2003. FAO Food and Nutrition Paper 81. Food and Agriculture Organization of the United Nations, Rome, Italy; ISBN 92 5105162 3. Available from: http://www.fao.org/3/y5499e/y5499e00.htm\#Contents

Ferri F, Brera C, De Santis B, Fedrizzi G, Bacci T, Bedogni L, Capanni S, Collini G, Crespi E, Debegnach F, Ferdenzi P, Gargano A, Gattei D, Luberto F, Magnani I, Magnani MG, Mancuso P, Menotta S, Mozzanica S, Olmi M, Ombrini G, Sala O, Soricelli S, Vicentini M, Giorgi Rossi P (2017) Survey on Uurinary lŁevels of Aflatoxins in Pprofessionally eExposed $\underline{w} W$ Workers. Toxins 9(4):117. https://doi.org/10.3390/toxins9040117

Ghosh SK, Desai MR, Pandya GL and Venkaiah K (1997) Airborne aflatoxin in the grain processing industries in India. Am Ind Hyg Assoc J 58:583-586-

Giolo MP, de Oliveira CM, Bertolini DA, Campana Lonardoni MV, Gouveia MS, Pontes Netto D, Nixdorf SL, Machinski M (2012) Aflatoxin M1 in the urine of non-carriers and chronic carriers of hepatitis B virus in Maringa, Brazil. Brazilian Jøurnal of Pharmaceutical Sciences 48(3):447-451 doi 10.1590/s1984 82502012000300011. http://dx.doi.org/10.1590/S1984-82502012000300011 
Groopman JD (1994). Molecular dosimetry methods for assessing human aflatoxin exposures. In: Eaton DL, Groopman

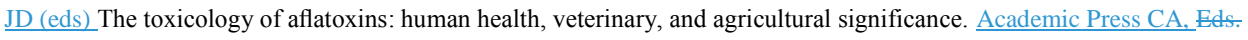
Eaton DL, Groopman JD.San Diego, CA: Academic Press.pp: 259-2이프

Groopman JD, Wild CP, Hasler J, Junshi C, Wogan GN, Kensler TW (1993) Molecular epidemiology of aflatoxin exposures: validation of aflatoxin-N7-guanine levels in urine as a biomarker in experimental rat models and humans. Environmental Health Perspectives_99:107_-113. https://doi.org/10.1289/ehp.9399107

IARC - International Agency for Research on Cancer [IARC] International Agency for Research on Cancer [IARC] (1993) Some naturally occurring substances: food items and constituents, heterocyclic aromatic amines and

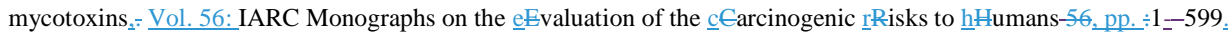
Available from: https://publications.iarc.fr/Book-And-Report-Series/Iarc-Monographs-On-The-Identification-Of-

Carcinogenic-Hazards-To-Humans/Some-Naturally-Occurring-Substances-Food-Items-And-Constituents-HeterocyclicAromatic-Amines-And-Mycotoxins-1993

Malik A, Ali S, Shahid M Bhargava R (2014) Occupational exposure to Aspergillus and aflatoxins among food-grain workers in India. Int J Occup Environ Health 20:189_-193_-

McLaughlin JK, Malker HSR, Malker BK, Stone BJ, Ericsson JLE, Blot WJ, Weiner JA, Fraumeni JF (1987) Registry-

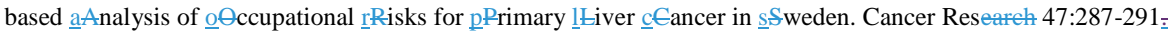

Olsen JH, Dragsted L, Autrup H (1988) Cancer risk and occupational exposure to aflatoxins in Denmark. British Jeurnal of Cancer 58:392-396-

Romero AC, Ferreira TRB, Dias CTS, Calori-Domingues MA, Gloria EM- (2010) Occurrence of AFM1 in urine samples of a Brazilian population and association with food consumption. Food Control 21:554-558

Saad-Hussein A, Beshir S, Moubarz G, Elserougy S and Ibrahim MI (2013) Effect of exposure to aflatoxins on some liver tumor markers in textile workers. Am J Ind Med 56:818-824

Saad-Hussein A, Taha MM, Beshir S, Shahy EM, Shaheen W, Elhamshary M (2014) Carcinogenic effects of aflatoxin

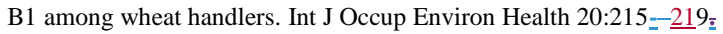

Stein RA, Bulboaca AE (2017) Mycotoxins. In: Dodd C, Aldsworth T, Stein R (eds) Foodborne Diseases, 3rd edn.-

Elseavier, San Diego, United States, Eds. Dodd C, Aldsworth T and Stein R. Chapter 21,pp 407-4446-, $3^{\text {Fd }}$ Ed

Sulyok M, Berthiller F, Krska R, Schuhmacher R (2006) Development and validation of a liquid chromatography/tandem mass spectrometric method for the determination of 39 mycotoxins in wheat and maize. Rapid Communication in Mass Spectrometry 20:2649-2659. https://doi.org/10.1002/rcm.2640 
Turner P, Flannery B, Isitt C, Ali M, Pestka J (2012) The role of biomarkers in evaluating human health concerns from fungal contaminants in food. Nutrition_Research Reviews 25(1):162-179. https://doi.org/10.1017/S095442241200008X Vidyasagar T, Sujatha N, Sashidhar RB (1997) Direct synthesis of aflatoxin $B_{1}-N^{7}$-Guanine adduct: a reference standard for biological monitoring of dietary aflatoxin exposure in molecular epidemiological studies. Food Additives and Contaminants 14(5):457-467. https://doi.org/10.1080/02652039709374552

Viegas S, Osteresch B, Hövelmann Y, Cebola de Oliveira A. Cramer B, Viegas C, Humpf HU (2017) Exposure to mycotoxins in Cork industry - The importance of a multibiomarker approach. $10^{\text {th }}$ International Symposium on Biological Monitoring in Occupational and Environmental Health. $4^{\text {st }}$ to 4 October in-Naples, Italy

Viegas S, Veiga L, Almeida A, dos Santos M, Carolino E and Viegas C (2016) Occupational exposure to aflatoxin B1 in a Portuguese poultry slaughterhouse. Ann Occup Hyg 60:176-183

Viegas S, Veiga L, Figueiredo P, Almeida A, Carolino E, and Viegas C (2014) Assessment of wWorkers’ Eexposure to Aflatoxin $B_{1}$ in a Portuguese $\# \underline{w}$ aste $\underline{i}$ Industry. The-Annals of Occupational Hygiene 59(2):173-_181.

https://doi.org/10.1093/annhyg/meu082

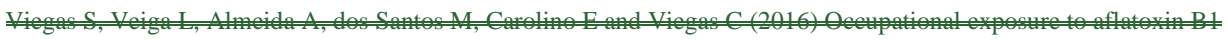

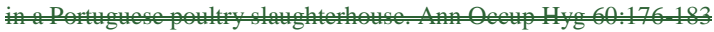

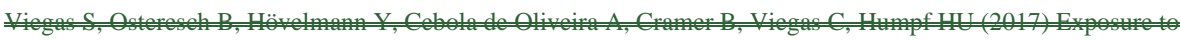

mycotoxins in Cork industry The importance of a multibiomarker approach. $10^{\text {th }}$ International Symposium on

Biological Menitoring in Oecepational and Environmental Health. $1^{\text {sf }}$ to 4 Oetober in Naples, Italy

Viegas S, Viegas $\mathrm{C}_{2}$ and Oppliger A (2018) Occupational exposure to mycotoxins: current knowledge and Pprospects. Annals of_Work Exposures and__Health 62(8)::923_-941. doi: 10.1093/annweh/wxy070 Walton M, Egner P, Scholl PF, Walker J, Kensler TW, Groopman JD (2001) Liquid chromatography electrospray-mass spectrometry of urinary aflatoxin biomarkers: characterization and application to dosimetry and chemoprevention in rats. Chem Res Toxicol 14:919--926

Wenzl T, Haedrich J, Schaechtele A, Robouch P, Stroka J (2016) Guidance Document on the Estimation of LOD and LOQ for Measurements in the Field of Contaminants in Feed and Food. EUR 28099, Publications Office of the European Union, Luxembourg ${ }_{\overline{-} .+}$ ISBN $978-92$ 79-61768 3. https://doi.org/10.2787/8931

Wild CP, Turner PC (2002) The toxicology of aflatoxins as a basis for public health decisions. Mutagenesis 17(6):471481. https://doi.org/10.1093/mutage/17.6.471 
547 Table 1. Distribution of the enrolled volunteers by group, age and body weight 


\begin{tabular}{rlccc}
8 & Controls group & $\underline{29}$ & $\underline{48(33-63)}$ & $\underline{83.4(64-125)}$ \\
9 & Total & $\underline{61}$ & $=$ & $=$ \\
\hline
\end{tabular}


1

2

3

4

5

\begin{tabular}{|c|c|c|c|c|}
\hline Compound & Chemical formula & Precursor ion $(\mathrm{m} / \mathrm{z})[\mathrm{M}+\mathrm{H}]^{+}$ & Fragment $(\mathbf{m} / \mathbf{z})$ & $\underline{\mathrm{NCE}}$ \\
\hline$\underline{\mathrm{AFB}}_{1}$ & $\underline{\mathrm{C}}_{17} \underline{\mathrm{H}_{12}} \underline{\mathrm{O}_{6}}$ & $\underline{313.07066}$ & $\underline{285.07571 ; 241.04952}$ & $\underline{25}$ \\
\hline${ }^{13} \mathrm{C}_{17}-\mathrm{AFB}_{1}$ & $\underline{\mathrm{C}_{17}} \underline{\mathrm{H}_{12}} \mathrm{O}_{6}$ & $\underline{330.12770}$ & $=$ & $=$ \\
\hline$\underline{\mathrm{AFM}_{1}}$ & $\underline{\mathrm{C}_{17}} \underline{\mathrm{H}_{12}} \underline{\mathrm{O}}_{7}$ & $\underline{329.06558+351.04752^{\mathrm{b}}}$ & $\underline{273.07538 ; 229.04937}$ & $\underline{27}$ \\
\hline${ }^{13} \mathrm{C}_{17}-\mathrm{AFM}_{1}$ & $\underline{\mathrm{C}}_{17} \underline{\mathrm{H}_{12}} \underline{\mathrm{O}}_{6} \underline{\underline{6}}$ & $\underline{346.12261+368.10456^{\mathrm{b}}}$ & $=$ & $=$ \\
\hline $\mathrm{AFB}_{1}-\mathrm{N}^{7}$-Guanine & $\underline{\mathrm{C}_{22}} \underline{\mathrm{H}_{17}} \underline{\mathrm{N}_{5}} \underline{\mathrm{O}_{8}}$ & $\underline{480.11499}$ & $\underline{152.05678,165.05499}$ & $\underline{40 ; 90}$ \\
\hline
\end{tabular}

aNormalised Collision Energy; ${ }^{b}[\mathrm{M}+\mathrm{Na}]^{+}$ 
1

2

3

4

5

7
596

599

10

11

12

13

14

15

16

17

18

$5 p 9$

208

602

23

24

625

264

38

648

64

643

44

45

646

67

48
649

64

58

622

53

54

55

56

57

58

59

60

61

62

63

64

65

$\underline{\text { Table } 3 \text { Calibration curve range, labelled internal standard concentration and correlation coefficients }}$

obtained for each mycotoxin/matrix combination are reported

\begin{tabular}{|c|c|c|c|c|c|c|}
\hline \multirow[t]{2}{*}{ Method } & \multicolumn{2}{|c|}{$\frac{\text { Calibration curve range }}{(\mathrm{pg} / \mathrm{mlL})}$} & \multicolumn{2}{|c|}{$\frac{\text { Labelled standard }}{\underline{(\mathrm{pg} / \mathrm{mlL})}}$} & \multicolumn{2}{|c|}{$\underline{\mathbf{R}^{2}(\mathrm{RSD}, \%)}$} \\
\hline & $\underline{\mathbf{A F B}_{1}}$ & $\underline{\mathbf{A F M}_{1}}$ & $\underline{\mathrm{U}-\left[{ }^{13} \mathrm{C}_{17}\right]-\mathrm{AFB}}{ }_{1}$ & $\underline{\mathrm{U}-\left[{ }^{13} \mathrm{C}_{17}\right]-\mathrm{AFM}}$ & $\underline{\mathbf{A F B}_{1}}$ & $\underline{\mathbf{A F M}_{1}}$ \\
\hline Dilute\&shoot & $\underline{5-100}$ & $\underline{10--200}$ & $\underline{10}$ & $\underline{20}$ & $\underline{0.9965(0.04)}$ & $\underline{0.9967(0.20)}$ \\
\hline$\underline{\text { IAC }}$ & $2.5-50$ & $\underline{5-100}$ & $\underline{50}$ & $\underline{100}$ & $\underline{0.9973(0.09)}$ & $\underline{0.9976(0.10)}$ \\
\hline
\end{tabular}


1

2

3

4

5

622

629

10

11

12

13

14

15

16

17

18

19

20

624

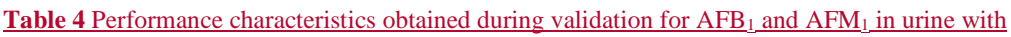
dĐilute\&shoot and-Shotand IAC clean-up methods

\begin{tabular}{lcccc}
\hline & \multicolumn{2}{c}{ DDilute\&shoot method } & \multicolumn{2}{c}{$\underline{\text { IAC clean-up method }}$} \\
& $\underline{\text { AFB }_{1}}$ & $\underline{\mathbf{A F M}_{1}}$ & $\underline{\text { AFB }_{1}}$ & $\underline{\text { AFM }_{1}}$ \\
\hline$\underline{\text { LOD }\left(\mathrm{pg} / \mathrm{mLL}_{\text {urine }}\right)}$ & $\underline{20}$ & $\underline{40}$ & $\underline{0.8}$ & $\underline{1.5}$ \\
$\underline{\text { LOQ }\left(\mathrm{pg} / \mathrm{mLL}_{\text {urine }}\right)}$ & $\underline{50}$ & $\underline{100}$ & $\underline{2.5}$ & $\underline{5.0}$
\end{tabular}
$\underline{\text { Working range }} \quad \underline{50.0-1000.0} \quad \underline{100.0-2000.0} \quad \underline{2.5-25.0} \quad \underline{5.0-50.0}$ (pg/mLl urine $)$ $\underline{\mathbf{R}_{\mathrm{A}}(\%)}$

$\underline{\mathbf{R}_{\mathrm{E}}(\%)}$

$\underline{\operatorname{SSE}(\%)}$

$\operatorname{RSD}_{\mathrm{r}}(\%)$

$=$
$=$
$\frac{111}{11}$

$\underline{101}$

$\underline{98}$

$=$

$=$

$\underline{82}$

$\underline{97}$

$\underline{104}$

$\underline{8} \quad \underline{11}$

$\underline{6}$

$\underline{12}$ 
1

2

3

4

5

$64 \frac{7}{8}$

649

10

11

12

13

14

645

646

659

651
18

659

250

682

23

24

625

269

688

29

30

60

32

33

664

35

36

634

38

39

$6 \$ 0$

657

648

44

45

646

47

48

649

50

68

53

54

55

56

57

58

59

60

61

62

63

64

65

$\underline{\text { Table 5. Percentage of positive samples, maximum values found and mean values (LB-UB) for AFM }} 1 \underline{\text { in workers group }}$ $\underline{\text { samples }}$

\begin{tabular}{|c|c|c|c|}
\hline & Positive $^{\mathrm{a}}(\%)$ & $\underline{\operatorname{Max}^{\mathrm{b}}(\mathrm{pg} / \mathrm{mL} \text { urine })}$ & Mean (LB-UB) (pg/mLurine) \\
\hline Monday and Friday; subjects $(\mathrm{n}=63)$ & $\underline{13}$ & $\underline{10.5}$ & $\underline{0.5-4.9}$ \\
\hline Monday; subjects $(\mathrm{n}=32)$ & $\underline{13}$ & $\underline{4.6^{\mathrm{c}}}$ & $\underline{0.4-4.48}$ \\
\hline Friday; subjects $(n=31)$ & $\underline{13}$ & $\underline{10.5}$ & $\underline{0.6-5.0}$ \\
\hline
\end{tabular}

Positive: values above LOD

maximum value

alue below the LOQ 
1

2

3

4

5

675

678

11

12

13

14

675

678

679

6B\%

6p9

680

684

682

23

24

685

26

2

688

29
30

31

32

33

34

35

36

37

38

39

40

41

42

43

44

45

46

47

48

49

50

51

52

53

54

55

56

57

58

59

60

61

62

63

64

65

Table 6. Percentage of positive samples, maximum values found and mean values (LB-UB) for $\mathrm{AFM}_{1} \underline{\text { in }}_{\text {controls group }}$ $\underline{\text { samples }}$

\begin{tabular}{|c|c|c|c|}
\hline & Positive $^{\mathrm{a}}(\%)$ & $\operatorname{Max}^{\mathrm{b}}\left(\mathrm{pg} / \mathrm{mL}_{\text {urine }}\right)$ & Mean (LB-UB) (pg/mLurine) \\
\hline Monday and Friday; subjects $(n=57)$ & $\underline{11}$ & $\underline{4.1}$ & $\underline{0.3-4.8}$ \\
\hline Monday; subjects $(n=29)$ & $\underline{7}$ & $\underline{2.8^{\mathrm{c}}}$ & $\underline{0.2-4.8}$ \\
\hline Friday; subjects $(n=28)$ & $\underline{14}$ & $\underline{4.1^{\mathrm{c}}}$ & $\underline{0.4-4.7}$ \\
\hline
\end{tabular}

Positive: values above LOD

below the LOQ 
$3^{\text {RD }}$ REV (letter 19/12/2019)

Reviewers' comments:

1. Delete heading "Conclusions", this journal has no such section. Concluding remarks should be put directly after end of results and discussion. DONE

2. Do not use justified text, but type left-aligned throughout the manuscript without automated hyphenation (?). Then please check if some typos (extra space etc) become visible and correct im necessary. DONE

3. Move "Acknowledgements" section directly before the reference list section DONE

4. Temperature and other units: consistently add one space between number and unit, for example " $2{ }^{\circ} \mathrm{C}$ ". Only \% should be placed directly at the number, for example "98.3\%" DONE

5. Consistently use only SI units, for example L119 $100 \mathrm{mmol} / \mathrm{L}$ phosphate, and look for other occurrences as well. DONE

6. L124 what does "Guanine dissolved in $0.1 \mathrm{~N} \mathrm{HCl}(0.32 \mu$ moles)" mean? a "mol" has no plural, just numbers. Replace $\mathrm{N}$ with $\mathrm{mol} / \mathrm{L}$ DONE

7. Check reference list again carefully and correct/modify according to examples as given in the instructions for authors of this journal (for example, EU regulations, EC-regulations, FAO documents). Remove issue numbers in brackets, not necessary. At present, reference list is full of typos etc. NO capitals in reference text except first word. DONE

8. Figure legends should be placed on a separate page not directly at figures. There is a supplementary file in the first revision named capture list but this appears to be empty. Please place list of figure captions after the references on a separate page in the manuscript, before the tables. DONE

9. Tables: just 3 horizontal lines, one above and one below the main table body, and one separating the first parameter row from the data entries. No extra horizontal lines in the main table body. Tables 1 and 2 are ok. DONE 
Figure 1
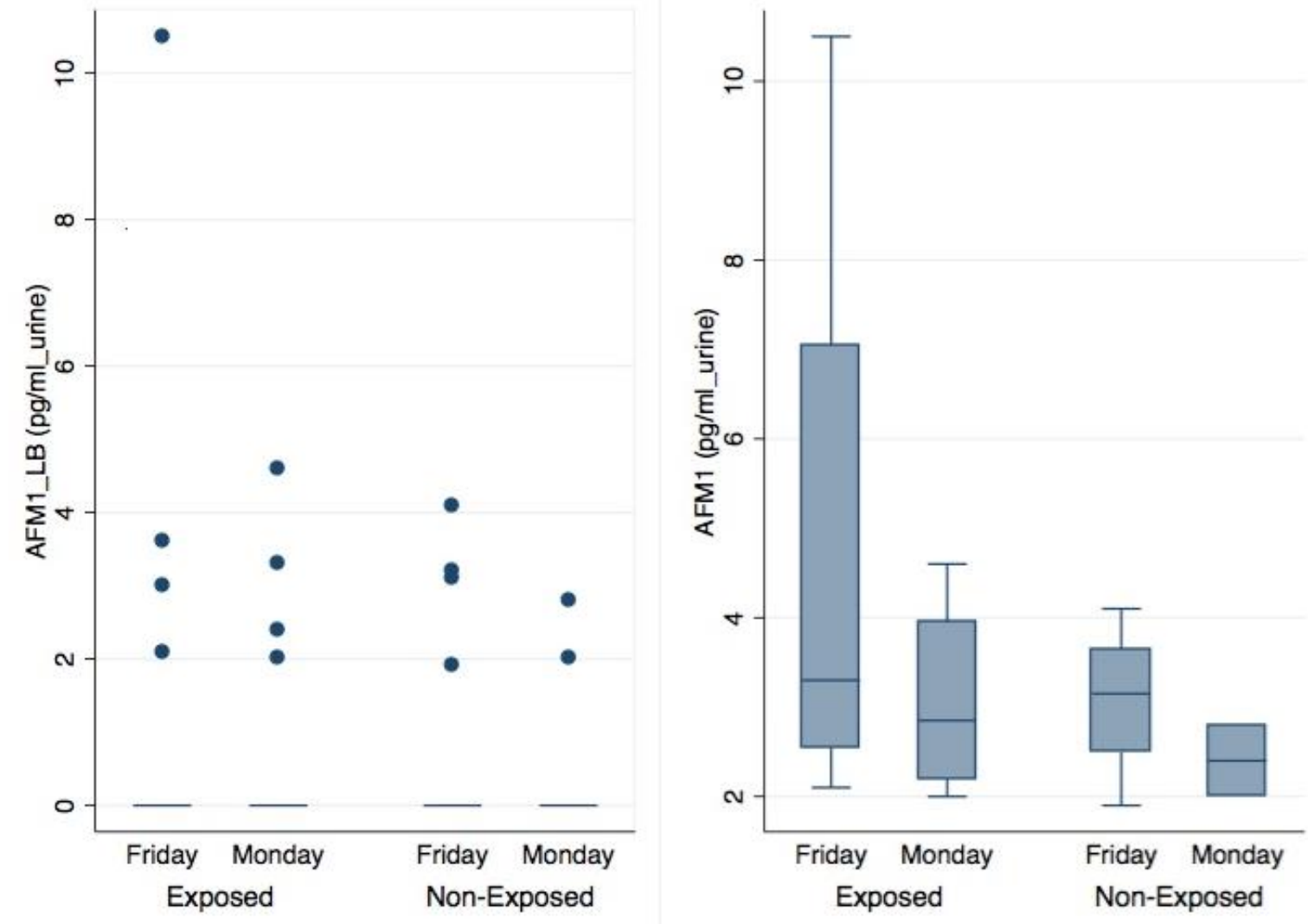


\section{Dear Editor}

Please find enclosed the revision of the research paper entitled "Optimization and validation of a LC-HRMS method for aflatoxins determination in urine samples" done following the comments from reviewers (letter 19 Dec 2019).

I thank you again for the opportunity to publish the manuscript in your respected journal.

Sincerely yours

Barbara De Santis 